\title{
Effects of limits in milking capacity, housing capacity, or fat quota on economic optimization of dry period lengths
}

Pornpamol Pattamanont $\odot$ and Albert De Vries* ${ }^{*}$

Department of Animal Sciences, University of Florida, Gainesville 32611

\section{ABSTRACT}

The economically optimal dry period length (DPL) of dairy cows remains a topic of interest. Increasing daily milk production and improved management of the transition period require frequent evaluation of the optimal DPL. The economically optimal DPL also depends on the most limiting farm resource such as milking capacity, housing capacity, or fat quota. Therefore, the objective of this study was to determine economically optimal DPL under farm constraints on milking capacity, housing capacity, and fat quota given variations in 12 input factor levels. We developed a deterministic whole herd simulation model, including a nonlinear optimizer of the DPL in the first 3 parities. The model included estimates of milk, fat, and protein yield deviations in the subsequent parity and hazard ratios of culling risk and pregnancy rates as functions of the DPL in the current parity. The DPL could vary between 20 and $90 \mathrm{~d}$ with step size of $1 \mathrm{~d}$. In addition to a one-factor-at-a-time analysis, we used a definitive screening design and a space-filling design with Latin hypercube sampling to determine important linear and curvature effects of input factors and their interactions. Results indicated that the economically optimal DPL were typically between 35 and $50 \mathrm{~d}$ under a large variation in input factor levels. The opportunity costs of equal DPL in all parities were small compared with optimal policies where the DPL were allowed to vary between parities. The DPL under the parlor constraint were generally less than $5 \mathrm{~d}$ longer than the optimal DPL under the housing constraint. The optimal DPL under the quota constraint were between those under the parlor and housing constraints. Opportunity costs compared with $50 \mathrm{~d}$ dry were often small, but in some cases large. A formal global sensitivity analysis revealed important interactions of input factors that were not

Received January 2, 2021.

Accepted June 16, 2021.

*Corresponding author: devries@ufl.edu discovered with one-factor-at-a-time analyses. In conclusion, economically optimal DPL were often shorter than typically are recommended. Adding uncertainty about the date of calving at the date of dry-off might extend these optimal DPL by some days depending on the risk attitude of the decision maker.

Key words: dry period, economics, profit, limit

\section{INTRODUCTION}

The economically optimal dry period length (DPL) remains a topic of interest. Since its adoption during World War II, a 60-d dry period has been advised as the DPL that maximizes lifetime production and genetic progress (Knight, 1998; Collier et al., 2012). On average, dairy farmers heed this advice. Recently, we found average DPL of 54,57, and $58 \mathrm{~d}$ for parities 1, 2, and 3 and greater (Pattamamont et al., 2021b). However, field data show large ranges of DPL (Pinedo et al., 2011; Pattamanont et al., 2021b).

Increasing daily milk yields and improvements in the management of transition cows continue to spark research into the optimal DPL. Several reviews discuss the physiology related to short or omitted DPL (e.g., Bachman and Schairer, 2003; Collier et al., 2012; van Knegsel et al., 2013; Kok et al., 2019). Briefly, these reviews show that short or omitted DPL increase the total milk yield in the parity before the DPL but reduce milk yield in the subsequent parity. However, short or omitted DPL improve the cow's energy balance, leading to improved health and fertility in some but not all studies.

Economic evaluations of various DPL have received less attention in the literature. Dias and Allaire (1982) used field records to determine the DPL that maximized milk yield over 2 consecutive parities. The optimum DPL varied from 0 to 78 d. Similarly, O'Connor and Oltenacu (1988) determined the DPL that optimized the net revenue in 2 consecutive parities using deterministic simulation modeling. Their economically optimum DPL varied between 47 and 63 for first-parity cows and 48 to $130 \mathrm{~d}$ for mature cows. Sørensen et al. 
(1993) pointed to the need for a farm level evaluation of the DPL when dry-off decisions for individual cows affect the impact of dry-off decisions for other cows. This situation occurs when cows in the farm use the same, limited resources. Using a stochastic dynamic herd simulation model, they found that a DPL of $7 \mathrm{wk}$ (49 d) was often preferable under limits on herd size or milk quota. Sørensen et al. (1993) concluded that the optimal DPL seemed to be shorter when evaluated at the farm level than when evaluated at the cow level. Santschi et al. (2011) completed cash flow calculations on 850 cows in 13 herds in Canada that were assigned either a DPL of 35 or $60 \mathrm{~d}$. Both a fat quota and a herd size constraint were considered. The short 35-d DPL was more profitable in both situations, but there was considerable variation among herds. Heeren et al. (2014) compared a 60-d DPL with 0-d DPL using a whole farm linear programming model. Under the milk quota constraint, the 0-d DPL was more profitable than the 60-d DPL. Under herd size and land constraints, the 0-d DPL was profitable if the cull rate was at least $3 \%$ lower than in the 60-d DPL situation. Finally, Kok et al. (2017) found that DPL of 28 and $0 \mathrm{~d}$ reduced profit compared with a 56-d DPL when herd size was the limiting factor.

These economic evaluations show large variations in approach and assumptions and consequently find economically optimal DPL that vary from no dry period to DPL longer than the conventional 50 to $60 \mathrm{~d}$. In addition, 3 studies recognized that the optimal DPL may depend on the farm constraint. A farm constraint is defined as the most limiting farm resource that prevents further growth of the farm, such as a fixed herd size (housing capacity) or a fat quota. Milking capacity is often a limiting factor on larger dairy farms, but economically optimal DPL when milking capacity is limiting were not found in the literature. Our hypothesis is that the economically optimal DPL is longer under a milking capacity constraint than under a housing or fat quota constraint. Although economically optimal DPL are of primary interest, losses from not following the optimal DPL settings are also of interest. Small opportunity costs imply that deviations from the optimal DPL have little effect on farm profitability.

Hence, the first objective of this study was to determine the economically optimal DPL under farm constraints on milking capacity, housing capacity, and fat quota. The second objective was to determine the opportunity cost of using nonoptimal DPL. The third objective was to identify the most important factors that determine the optimal DPL and opportunity costs. For this third objective, we followed a formal sensitivity analysis process to identify nonlinear and interactions effects.

\section{MATERIALS AND METHODS}

\section{Model Overview}

We developed a deterministic Markov chain herd budget model to evaluate the technical and economic consequences of variations in DPL for each parity. The model included daily steps of cows moving probabilistically through parities with lactating and dry periods. A single number of days to conception in each parity was calculated given the voluntary waiting period, pregnancy rate, and hazard ratio of pregnancy conditional on DPL. We varied DPL and consequently, the DIM at dry-off in each parity was determined. Daily hazards of culling reduced the probability that cows remained in the herd. The model had separate technical and price inputs for the first 4 parities (described below) to limit the number of inputs and calculations. Performance in parity 5 and greater was therefore the same as in parity 4. The model calculated metrics such as the number of milking and dry cows and fat yield, and financial metrics such as farm profit. Variations in DPL affected cow performance through effects on hazards of pregnancy, hazards of culling, and milk, fat, and protein yields (described below). Input functions and parameters for technical performance were chosen from the literature and based on the authors' experiences to represent a typical Holstein herd in the United States. Input prices aimed to reflect typical prices observed or expected in the last $5 \mathrm{yr}$ and found in VanRaden et al. (2018), USDA-AMS (2020), and USDA-ERS (2020). Baseline cost assumptions were also based on Karzes et al. (2020). Bruno do Amaral, Progressive Dairy Solutions (Oakdale, CA), assisted with selection of baseline feed and other variable costs.

\section{Model Description}

Reproduction. Modifying the equation for pregnancy rate in VanRaden et al. (2011), we calculated days open $=[21 /$ (pregnancy rate $\times$ hazard ratio $)+$ voluntary waiting period -11$]$. Here, days open is the number of days from calving to conception, and the voluntary waiting period is the number of days from calving to the start of the breeding period. Pregnancy rate is the probability an eligible open cow becomes pregnant in a $21-d$ period. We set the baseline values for voluntary waiting periods at $60 \mathrm{~d}$ and the pregnancy rate at $22 \%$ for parity 2 (DRMS, 2020). Pregnancy rates for parities 1, 3, and 4 were respectively set at 108, 93, and $86 \%$ of the parity 2 pregnancy rate, based on lower conception rates for greater parity cows (DRMS, 2020).

The hazard ratio of pregnancy rate in the subsequent parity is predicted by 3 quadratic functions of the DPL 
in the current parity (Pattamanont et al., 2021a). By definition, the hazard ratio was 1 when DPL was 50 d. Shorter DPL had hazard ratios $>1$ and longer DPL had hazard ratios $<1$. Thus, shorter DPL reduced days open. Gestation length was set at $280 \mathrm{~d}$.

To determine total cost of inseminations, we calculated the number of inseminations per pregnancy as (days open - voluntary waiting period) $/ 21 \times$ estrus detection rate. Estrus detection rate was set at $60 \%$. Cost of an insemination was $\$ 20$. We set the value of a calf at $\$ 150$. The cost of a calving event was set at $\$ 150$ to account for additional labor and supplies and contribution to fixed costs.

Culling. The daily hazard of culling varied by days since calving, pregnancy status, parity, and DPL in the previous parity. The annualized risk of culling of an open cow (De Vries et al., 2010) was set at 45\%, which implies a daily hazard of $1-(1-0.45)^{1 / 365}=0.164 \%$ that an open cow gets culled. Cows that were not culled this way became pregnant. The daily culling hazard for pregnant cows was set at $25 \%$ of the daily hazard of culling for open cows (De Vries et al., 2010). The risk of culling increased with parity:hazard ratios of cows not completing the parity were $1,1.20,1.54$, and 1.99 for parities 1 to 4 or more, respectively, based on Norman et al. (2020). The annual cull rate was calculated as the number of cows culled divided by the average number of cows present in a year.

The number of cows in parities 5 and greater was calculated as $\sum_{i=1}^{N}(1-\% \text { culled } 4)^{i}$, where $N$ is the number of future parities and \%culled4 is the percentage of cows that started but did not complete the fourth parity. The baseline value of \% culled4 was $69.4 \%$. We set $N$ as large, such that $(1-\% \text { culled } 4)^{N}$ is very small. The result of this calculation was that for every cow in parity 4 , there were 1.44 cows in parities 5 and greater.

The effect of DPL in the current parity on the hazard of culling in the subsequent parity was predicted by 9 quadratic functions (Pattamanont et al., 2021a). The parameters of the quadratic functions depended on 3 stages of lactation (1-60 d, 61-250 d, and $\geq 251 \mathrm{~d}$ ) for 3 parities. All 9 hazard ratios were 1 when DPL in the previous parity was $50 \mathrm{~d}$. When DPL was $20 \mathrm{~d}$, hazard ratios varied from 0.74 to 1.14 . When DPL was $90 \mathrm{~d}$, the hazard ratios varied from 1.00 to 1.47 . The daily baseline hazard was multiplied by the hazard ratio from the relevant quadratic function to account for the association between DPL and the risk of culling.

Salvage value of a culled cow was calculated as $\$ 1.50 / \mathrm{kg}$ of BW (described below), which accounts for death losses without revenue. Cost of a calving replacement heifer that immediately replaced a culled cow was $\$ 1,800$.

\section{Milk, Fat, and Protein Production}

Lactation curves for fat yield, protein yield, and milk yield depended on parity, DIM, days pregnant, and DPL in the previous parity. Yields per DIM were modeled with the 4-parameter MilkBot model (Ehrlich, 2011) for parities 1 to 4. The parameters (Appendix Table A1) were estimated on the same data that were used to estimate changes in milk yield in the subsequent parity associated with different DPL (Pattamanont et al., 2021b). These yields represent yields of open cows when DPL in the previous parity was $50 \mathrm{~d}$.

Pregnancy reduced first-parity milk yield by 0.03 $\mathrm{kg} / \mathrm{d}$, and fat and protein yields by $0.0009 \mathrm{~kg} / \mathrm{d}$, both after $120 \mathrm{~d}$ pregnant, based on Bohmanova et al. (2009). At $220 \mathrm{~d}$ pregnant, reductions in milk, fat, and protein were therefore $3,0.09$, and $0.09 \mathrm{~kg}$, respectively, compared with nonpregnant cows at the same DIM. Based on Leclerc et al. (2008), we set the reduction in milk yield due the pregnancy in multiparous cows at $0.04 \mathrm{~kg} / \mathrm{d}$, and fat and protein yields at $0.0012 \mathrm{~kg} / \mathrm{d}$, both after $120 \mathrm{~d}$ pregnant.

We used our piecewise functions of milk, fat, and protein mature equivalent 305 -d yield deviations (Pattamanont et al., 2021b) to model the effects of DPL on yields in the subsequent parity. Yield deviations were 0 $\mathrm{kg}$ when DPL were $50 \mathrm{~d}$. Generally, shorter DPL had greater negative yield deviations (losses) when DPL in the previous parity were shorter than approximately 50 DIM. Yield deviations often were marginally positive and increasing for DPL >50 d. Mature equivalent 305-d yield deviations were converted to actual 305-d yield deviations through multiplications by $82,95,100$, and $100 \%$ for parities 1, 2, 3, and 4, respectively (Pattamanont et al., 2021b). Actual 305-d yields were divided by 305 to obtain daily yield deviations.

The piecewise functions of Pattamanont et al. (2021b) do not depend on level of production during the current parity or yield at dry-off. However, higher levels of milk production in the current parity increased yield deviations (Pattamanont et al., 2021b). Therefore, when a multiplier $\neq 1$ was used to increase or decrease the herd's level of milk production from the baseline, the same multiplier was used to adjust the daily yield deviations in the same way. Finally, the yield deviations were added to the default daily yield predictions to obtain daily yields in the subsequent parity.

Milk was priced as the sum of the value of fat $(\$ 5.50 /$ $\mathrm{kg}$ ) and protein $(\$ 5.30 / \mathrm{kg})$. Other (not feed) variable costs associated with lactating cows were $\$ 3 /$ lactating cow per day. These included cost for milking labor and parlor supplies, milk marketing, housing, health care, and labor. Other (not feed) variable costs associated with dry cows were set at $\$ 1.50 /$ dry cow per day. These 
costs included costs for housing, health care and labor. The cost of a dry-off event was set at $\$ 46$ and was the sum of costs for dry-off tubes, teat sealant, pregnancy check, hoof trimming, and vaccines.

Body Weight. We used the BW function described by Korver et al. (1985) fitted on the BW data in the NRC (2001). This function and these parameters were earlier used by De Vries (2006). The daily BW predictions through lactation were used when calculating DM feed intake and salvage values of culled cows.

Dry Matter Intake. Dry matter intake of lactating cows was calculated by the DMI function in the NRC (2001). This function takes as inputs daily 4\% FCM yield, BW, and week of lactation. Cows that produce less because of short DPL do not necessarily consume less DM in the subsequent parity (Rastani et al., 2005; Kok et al., 2017). We had no data on DMI in the subsequent lactation of cows that produce more because of longer DPL. Therefore, the daily $4 \%$ FCM yield was determined from the lactation curves for milk and fat but did not include yield deviations caused by variations in DPL from the default $50 \mathrm{~d}$. Dry matter intake for dry cows was set at $12.5 \mathrm{~kg} / \mathrm{d}$ for the $19 \mathrm{~d}$ before calving (close-up) and $13.5 \mathrm{~kg} / \mathrm{d}$ when the dry cow was at least $20 \mathrm{~d}$ before calving (far-off). Dry matter prices were set at $\$ 0.36 / \mathrm{kg}$ for cows fed the first 60 DIM, $\$ 0.36 / \mathrm{kg}$ for lactating cows from 60 to 200 DIM, and $\$ 0.26 / \mathrm{kg}$ for lactating cows after 200 DIM until dry-off. Dry matter prices were $\$ 0.22 / \mathrm{kg}$ for far-off dry cows and $\$ 0.26 / \mathrm{kg}$ for close-up dry cows.

Farm Constraints. We calculated farm profit as total revenues minus total costs. Profit metrics should be defined relative to the most limiting farm constraint (Barnard and Nix, 1979). Therefore, we defined 3 profit metrics: profit/milking cow per day, profit/cow per day, and profit $/ \mathrm{kg}$ of fat. The 3 profit metrics correspond to the farm constraints milking capacity, housing capacity, and fat quota, respectively. We refer to these 3 constraints as the parlor, housing, and quota constraints. We set the housing constraint at 1,000 cows. This resulted in 897.4 milking cows, and $1,180.5 \mathrm{~kg}$ of fat $/ \mathrm{d}$ when all factors were set at their baseline levels and DPL of $50 \mathrm{~d}$ were used. Therefore, we set the parlor constraint at 897.4 milking cows and the quota constraint at $1,180.5 \mathrm{~kg}$ of fat $/ \mathrm{d}$. Total costs were the sum of costs for calving, feed, inseminations, dry-off, and the other variable costs. Costs that were independent of the number of cows (fixed cost) were not included.

Optimization. We maximized the profit metric corresponding to the farm constraint of interest by varying the DPL between 20 and $90 \mathrm{~d}$ with step size of $1 \mathrm{~d}$ (71 steps per dry period per parity). The DPL in parities 3 and greater were set equal in all cases. Hence, profit maximization included search of the best DPL for the first 3 parities. Because the effect of the 3 DPL on profitability were not independent, the search consisted of $71^{3}=357,911$ combinations of the 3 DPL. An evaluation of all combinations was unfeasible. Therefore, and because the problem is nonlinear, we used a Generalized Reduced Gradient solver (FrontlineSolvers, 2020) to find the optimal DPL. A DPL policy is noted as XX-YY-ZZ. For example, the policy 45-50-60 implies DPL of 45,50 , and $60 \mathrm{~d}$ in the first 3 parities, respectively. In addition to finding the unrestricted optimal policy, we also conducted profit maximizations where the 3 DPL were required to be all equal. In addition, we evaluated the user-defined all-equal policies 20-20-20, 40-40-40, 50-50-50, 60-60-60, and 80-80-80 to determine opportunity costs. Opportunity cost was defined as the profit not realized because a user-defined policy is used instead of the unrestricted optimal policy.

\section{Design of Experiments}

We conducted sensitivity analyses because input factor values vary between farms and over time. There is also some uncertainty about our chosen baseline values. We identified 12 input factors, all described above, that might affect the optimal policy and opportunity costs of nonoptimal policies (Table 1): Milk components price multiplier (X1), feed cost low lactating cows (X2), other variable cost lactating cows (X3), cull risk open cows (X4), heifer price (X5), calf price (X6), other variable cost dry cows (X7), pregnancy rate (X8), herd milk yield multiplier (X9), hazard ratio of cull risk multiplier (X10), hazard ratio of pregnancy rate multiplier (X11), and milk components deviation in the subsequent parity multiplier (X12). All 12 factors are continuous.

Next, we designed computer experiments to identify the most important (active) factors and their interactions from among these 12 factors. The other aim of the experiments was to quantify the effects of the most important factors on the optimal policies and on the opportunity cost of alternate, nonoptimal, policies. For every factor, we calculated the lowest and highest levels as 67 and $133 \%$ of the baseline levels, respectively.

We first conducted a one-factor-at-a-time (OAT) analysis (Czitrom, 1999; Saltelli et al., 2019). Our OAT experimental design varied the 12 factors one by one, both at the lowest and highest level, leaving the other 11 input factors at their baseline levels. This OAT design takes 25 runs per farm constraint. An OAT design allows for identification of important main effects and curvature around the baseline but cannot effectively explore a multidimensional space, such as when interactions are present (Saltelli et al., 2019).

The second analysis aimed to identify the most important (active) effects, including interactions, to focus 
Table 1. Input factors, factor names, baseline values, and clarifying comments of factors used in the sensitivity analysis

\begin{tabular}{llcl}
\hline Factor & Factor name & Baseline & Comment \\
\hline X1 & Components price multiplier & 1 & Multiplier for fat and protein price \\
X2 & Feed cost low lactating cows, $\$ / \mathrm{kg} D \mathrm{D}$ & 0.26 & \\
X3 & Other variable cost lactating cows, $\$ /$ cow per d & 3.50 & Variable cost for lactating cows not included in any other \\
& & 45 & Cuctor \\
X4 & Cull risk open cows, $\% /$ yr & 1,800 & \\
X5 & Heifer price, $\$ /$ head & 150 & \\
X6 & Calf price, $\$ /$ head & 1.50 & Variable cost for dry cows not included in any other factor \\
X7 & Other variable cost dry cows, $\$ /$ cow per d & 22 & Pregnancy rate for second-parity cow \\
X8 & Pregnancy rate, $\%$ & 1 & Multiplier for 305-d milk yield \\
X9 & Milk yield multiplier & 1 & Multiplier for cull risk of open and pregnant cows \\
X10 & Cull risk multiplier & 1 & Multiplier for pregnancy rate \\
X11 & Pregnancy rate multiplier & 1 & Multiplier for fat and protein deviations in subsequent parity \\
X12 & Components loss multiplier & &
\end{tabular}

on a smaller subset of the 12 factors. If every factor is evaluated at 3 levels (a full factorial design) then $3^{12}=531,441$ runs are necessary. This setup was time prohibitive. Therefore, 2 screening designs were used.

In the first screening design, we implemented a definitive screening design (DSD, Jones and Nachtsheim, 2011) with the aim to identify important first-order main effects and second-order effects (quadratic terms and 2-way interactions). In this 12 -factor original DSD, every factor is evaluated at 3 levels, and the DSD implements 25 combinations of factor settings and thus uses 25 model runs (Figure 1 in Jones and Nachtsheim, 2011). When the number of active effects is greater than half the number of model runs, the DSD is not able to identify the most important effects (Errore et al., 2017). Preliminary analysis (not shown) indicated this was sometimes the case in our study. Therefore, a second screening design was added.

The second screening design consisted of 100 model runs with a space-filling design where the values of the 12 factors were independently and (pseudo) randomly chosen in between the lowest and highest levels (Santner et al., 2003). We used Latin hypercube sampling (LHS, McKay et al., 1979) to make the distribution of factor levels among the input space more equal. For both DSD and LHS, we standardized the factor levels to a mean of 0 and standard deviation of 1 using procedure STANDARD in SAS 9.4 (SAS Institute).

We defined 2 output metrics to quantify the effects of the 12 factors. The first metric was the DPL of the all-equal optimal policy when the levels of the 12 factors were varied. The second metric was the profit not realized (an opportunity cost) when the unrestricted optimal policy associated with the baseline factor settings is used, instead of the unrestricted optimal policy associated with the factor settings of the run. Both metrics were used for the analysis of the DSD and LHS designs.
Following the suggestion of Jones and Nachtsheim (2011), we used forward stepwise selection with full second-order models (interaction, all main effects, quadratic effects, and 2-way interactions; 91 effects in total) of the 12 factors to determine the most important effects in the DSD and LHS designs. We used Akaike's information criterion with small sample correction to determine the order in which the effects entered the model (Errore at al., 2017). We stopped model building when 9 effects had entered the model after the intercept was added first. The strengths of the effects were compared by the order in which they entered the model, and their standardized regression coefficients (Saltelli et al., 2004). We conducted the forward selection regression analysis with procedure GLMSELECT in SAS.

Following the screening designs, we investigated the output metrics of the 3 most active interactions using full factorial designs at 3 levels (low, baseline and high levels, $3^{2}=9$ runs per interaction). All designed experiments were conducted separately for the 3 farm constraints.

\section{RESULTS}

\section{Baseline Settings}

Table 2 shows technical output metrics for parities 1 to 4 and greater when the baseline factor levels are used with a 50-50-50 policy. These metrics do not depend on the farm constraints and may serve for validation. Table 3 shows financial metrics at the baseline factor levels and a 50-50-50 policy. Financial results are expressed per herd per day, per $100 \mathrm{~kg}$ of milk, per milking cow per day, per cow per day, and per $\mathrm{kg}$ of fat. All 3 farm constraints are simultaneously binding. All costs metrics depend on the DPL policy.

Table 4 shows results for 5 user-defined policies ranging from $20-20-20$ to $80-80-80$. The results for 
Table 2. Technical metrics per parity and for the herd for the baseline inputs and a dry period length policy of $50-50-50^{1}$

\begin{tabular}{|c|c|c|c|c|}
\hline Metric & Parity 1 & Parity 2 & Parity 3 & Parity $4+$ \\
\hline Pregnancy rate, $\%$ & 23.8 & 22.0 & 20.5 & 18.9 \\
\hline Days open & 137 & 144 & 152 & 160 \\
\hline DIM at dry-off & 367 & 374 & 382 & 390 \\
\hline Calving interval, $\mathrm{d}$ & 417 & 424 & 432 & 440 \\
\hline Milk, kg/milking cow per day & 32.21 & 36.58 & 38.30 & 38.98 \\
\hline Fat, $\mathrm{kg} /$ milking cow per day & 1.21 & 1.36 & 1.42 & 1.45 \\
\hline Protein, kg/milking cow per day & 0.99 & 1.13 & 1.17 & 1.17 \\
\hline Lactating DMI, kg/milking cow per day & 21.5 & 21.4 & 21.3 & 20.8 \\
\hline $\mathrm{BW}, \mathrm{kg} / \mathrm{cow}$ & 571 & 630 & 630 & 627 \\
\hline Cows, $\%$ & 43.5 & 30.0 & 17.3 & 9.2 \\
\hline Milking cows, $\%$ & 89.1 & 89.6 & 90.4 & 92.0 \\
\hline Annual cull rate, $\%$ & 27.1 & 34.2 & 47.1 & 69.4 \\
\hline Cost per dry day, $\$$ & 5.50 & 5.51 & 5.51 & 5.51 \\
\hline Milk yield at dry-off, $\mathrm{kg}$ & 25.05 & 24.63 & 24.22 & 23.74 \\
\hline Lactating IOFC ${ }^{2}$ at dry-off, $\$ / \mathrm{d}$ & 4.46 & 4.75 & 4.59 & 4.18 \\
\hline Dry IOFC at dry-off, $\$ / \mathrm{d}$ & -3.25 & -3.25 & -3.25 & -3.25 \\
\hline$\Delta$ IOVC $^{3}$ at dry-off, $\$ / \mathrm{d}$ & -6.21 & -6.50 & -6.34 & -5.93 \\
\hline
\end{tabular}

${ }^{1}$ A dry period length policy of 50-50-50 implies $50 \mathrm{~d}$ dry in parities 1,2 , and $3+$, respectively; the results do not depend on the constraint (parlor, housing, or quota).

${ }^{2} \mathrm{IOFC}=$ income over feed cost $=$ milk sales minus feed cost.

${ }^{3} \Delta$ IOVC $=$ change in income over variables cost $=$ change in milk sales minus variable cost, immediately before and after dry-off.

the 50-50-50 policy are for the same factor settings as used in Tables 2 and 3. Short DPL resulted in shorter days open, but later DIM at dry-off. Daily milk yield at dry-off increased from 23.10 to $26.42 \mathrm{~kg}$ from shortest to longest DPL. Annual cull rates varied little with the policy, ranging from 38.6 to $40.4 \%$. Compared with the 50-50-50 policy, the average cow in the 20-20-20 policy lost more milk in the subsequent parity $(-1,053$ $\mathrm{kg}$ ) than the extra milk made in the current parity $(+618 \mathrm{~kg})$. For the 40-40-40 policy, the average cow lost less milk in the subsequent parity $(-174 \mathrm{~kg})$ than the extra milk made in the current parity $(+212 \mathrm{~kg})$. Cows with longer DPL made more milk in the subsequent parity $(+36$ and $+103 \mathrm{~kg}$, respectively), but made less milk in the current parity $(-220$ and -686 $\mathrm{kg}$, respectively). These results do not depend on the type of farm constraint.

When the parlor constraint was binding, the number of cows and fat yield increased with longer DPL (Table 4). Profit/milking cow per day was greatest with the 40-40-40 policy compared with the other 4 userdefined policies. The opportunity cost of a 50-50-50

Table 3. Financial metrics for the herd at baseline input levels and a dry period length policy of 50-50-50

\begin{tabular}{lrrrrr}
\hline Metric & $\begin{array}{c}\$ / \text { herd } \\
\text { per d }\end{array}$ & $\begin{array}{c}\$ / 100 \mathrm{~kg} \\
\text { of milk }\end{array}$ & $\begin{array}{c}\$ / \text { milking } \\
\text { cow per d }\end{array}$ & $\begin{array}{c}\$ / \text { cow } \\
\text { per d }\end{array}$ & $\begin{array}{c}\$ / \mathrm{kg} \\
\text { of fat }\end{array}$ \\
\hline $\begin{array}{l}\text { Revenue } \\
\text { Cull sales }\end{array}$ & 1,154 & 3.65 & 1.29 & 1.15 & 0.98 \\
$\quad$ Calf sales & 449 & 1.58 & 0.56 & 0.50 & 0.42 \\
$\quad$ Milk sales & 11,647 & 36.85 & 12.98 & 11.65 & 9.87 \\
Costs & & & & & \\
$\quad$ Calvings & 499 & 1.58 & 0.56 & 0.50 & 0.42 \\
Heifers & 2,324 & 7.35 & 2.59 & 2.32 & 1.97 \\
$\quad$ Lactating feed & 6,063 & 19.18 & 6.76 & 6.06 & 5.14 \\
Dry feed & 316 & 1.00 & 0.35 & 0.32 & 0.27 \\
$\quad$ Reproduction & 114 & 0.36 & 0.13 & 0.11 & 0.10 \\
Other variable cost lactating cows & 2,692 & 8.52 & 3.00 & 2.69 & 2.28 \\
Other variable cost dry cows & 154 & 0.49 & 0.17 & 0.15 & 0.13 \\
$\quad$ Dry-off & 95 & 0.30 & 0.11 & 0.10 & 0.08 \\
Profit & 1,042 & 3.30 & 1.16 & 1.04 & 0.48 \\
$\quad$ Revenue minus costs & & & & & \\
\hline
\end{tabular}

${ }^{1}$ A dry period length policy of 50-50-50 implies $50 \mathrm{~d}$ dry in parities 1, 2, and 3+, respectively. All 3 constraints (parlor, housing, quota) are met simultaneously. 
policy was only $\$ 0.03 /$ milking cow per day. The opportunity cost of the $20-20-20$ and $80-80-80$ policies were $\$ 0.34$ and $\$ 0.42 /$ milking cow per day. When the housing constraint was binding, the number of milking cows decreased with longer DPL, but fat yield was the highest with the 40-40-40 policy. Profit/cow per day was greatest with the 40-40-40 policy. Opportunity cost of the 50-50-50 policy compared with the 40-4040 policy was $\$ 0.05 /$ cow per day. The quota constraint also resulted in the greatest profit with the 40-40-40 policy. Opportunity cost of the 50-50-50 policy was $\$ 0.03 / \mathrm{kg}$ fat. None of these 5 user-defined policies were optimal. The unrestricted and all-equal optimal policies for the baseline factor settings are shown in the first rows in Tables 5, 6, and 7 .

\section{One-Factor-at-a-Time Analysis}

Tables 5 (parlor), 6 (housing) and 7 (quota) show results of the OAT analyses. For the parlor constraint, the unrestricted and all-equal optimal policies for the baseline levels of the 12 factors were 43-44-40 and 43-43-43 (Table 5). Opportunity cost of the all-equal policy versus the unrestricted optimal policy was < $\$ 0.01 /$ milking cow per day. The opportunity cost of the 50-50-50 policy was $\$ 0.03 /$ milking cow per day. The opportunity costs of the $20-20-20$ and $80-80-80$ policies were $\$ 0.34$ and $\$ 0.43 /$ milking cow per day. For all 24 variations in factor levels, the optimal policies varied little from the optimal policies at the baseline factor settings. The all-equal optimal policies varied

Table 4. Technical and financial metrics for baseline inputs for 5 dry period length policies

\begin{tabular}{|c|c|c|c|c|c|}
\hline Herd metric & \multicolumn{5}{|c|}{ Dry period length policy ${ }^{1}$} \\
\hline Pregnancy rate, $\%$ & 22.8 & 22.2 & 22.0 & 21.8 & 21.6 \\
\hline DIM at dry-off & 401 & 384 & 375 & 366 & 347 \\
\hline Calving interval, $\mathrm{d}$ & 421 & 424 & 425 & 426 & 427 \\
\hline Milk, kg/milking cow per day & 32.49 & 34.64 & 35.22 & 35.52 & 36.08 \\
\hline Lactating DMI, $\mathrm{kg} /$ milking cow per day & 21.3 & 21.3 & 21.3 & 21.3 & 21.3 \\
\hline $\mathrm{BW}, \mathrm{kg} / \mathrm{cow}$ & 607 & 607 & 607 & 606 & 606 \\
\hline Milking cows, $\%$ & 95.9 & 91.8 & 89.7 & 87.7 & 83.6 \\
\hline Annual cull rate, $\%$ & 38.7 & 38.6 & 38.8 & 39.2 & 40.4 \\
\hline Milk yield at dry-off, $\mathrm{kg} / \mathrm{d}$ & 23.10 & 24.16 & 24.69 & 25.25 & 26.42 \\
\hline Lactating IOFC ${ }^{2}$ at dry-off, $\$ / \mathrm{d}$ & $\$ 3.28$ & $\$ 4.23$ & $\$ 4.55$ & $\$ 4.82$ & $\$ 5.30$ \\
\hline Dry IOFC at dry-off $+1, \$ / \mathrm{d}$ & -3.25 & -3.25 & -3.25 & -3.25 & -3.25 \\
\hline Herd cows, $\mathrm{n}$ & 935.5 & 977.6 & 1,000 & $1,023.4$ & $1,073.1$ \\
\hline Herd fat yield, $\mathrm{kg} / \mathrm{d}$ & $1,104.8$ & $1,165.2$ & $1,180.5$ & $1,188.7$ & $1,202.4$ \\
\hline Profit, $\$ /$ milking cow per day & 0.85 & 1.19 & 1.16 & 1.06 & 0.77 \\
\hline \multicolumn{6}{|l|}{ Housing constraint binding: } \\
\hline Herd milking cows, $\mathrm{n}$ & 959.2 & 918.0 & 897.4 & 876.9 & 836.2 \\
\hline Herd cows, $n$ & $1,000.0$ & $1,000.0$ & 1,000 & $1,000.0$ & $1,000.0$ \\
\hline Herd fat yield, $\mathrm{kg} / \mathrm{d}$ & $1,180.9$ & $1,192.0$ & $1,180.5$ & $1,161.5$ & $1,120.5$ \\
\hline Profit, $\$ /$ cow per day & $\$ 0.82$ & $\$ 1.09$ & $\$ 1.04$ & $\$ 0.93$ & $\$ 0.64$ \\
\hline \multicolumn{6}{|l|}{ Quota constraint binding: } \\
\hline Herd milking cows, $\mathrm{n}$ & 958.8 & 909.1 & 897.4 & 891.2 & 881.0 \\
\hline Herd cows, $n$ & 999.6 & 990.4 & 1,000 & $1,016.3$ & $1,053.5$ \\
\hline Herd fat yield, $\mathrm{kg} / \mathrm{d}$ & $1,180.5$ & $1,180.5$ & $1,180.5$ & $1,180.5$ & $1,180.5$ \\
\hline Profit, $\$ / \mathrm{kg}$ fat & 0.69 & 0.91 & 0.88 & 0.80 & 0.57 \\
\hline
\end{tabular}

${ }^{1} \mathrm{~A}$ dry period length policy of XX-YY-ZZ implies XX d dry in parity 1, YY d dry in parity 2, and ZZ d dry in parity $3+$.

${ }^{2} \mathrm{IOFC}=$ income over feed cost $=$ milk sales minus feed cost.

${ }^{3} \Delta$ IOVC $=$ change in income over variable costs = change milk sales minus variable costs immediately before and after dry-off.

${ }^{4} \Delta$ Milk made (current lact.) $=$ change in amount of milk made in the current parity vs. the amount of milk made with a 50-d dry period length per cow.

${ }^{5} \Delta$ Milk made (subseq. lact.) $=$ change in amount of milk made in the first $305 \mathrm{~d}$ in the subsequent parity vs. the amount of milk made with a 50 -d dry period length per cow. 


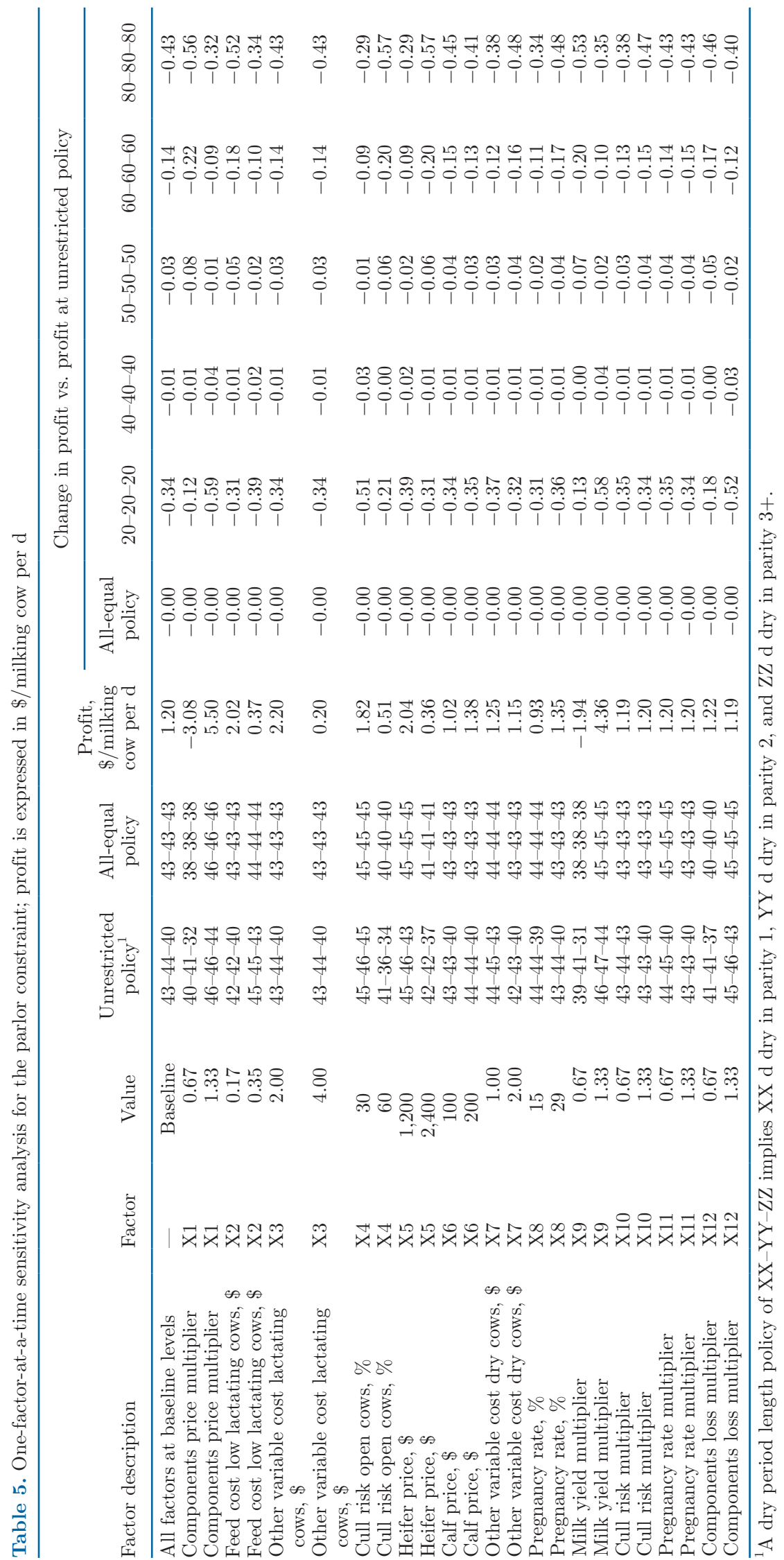




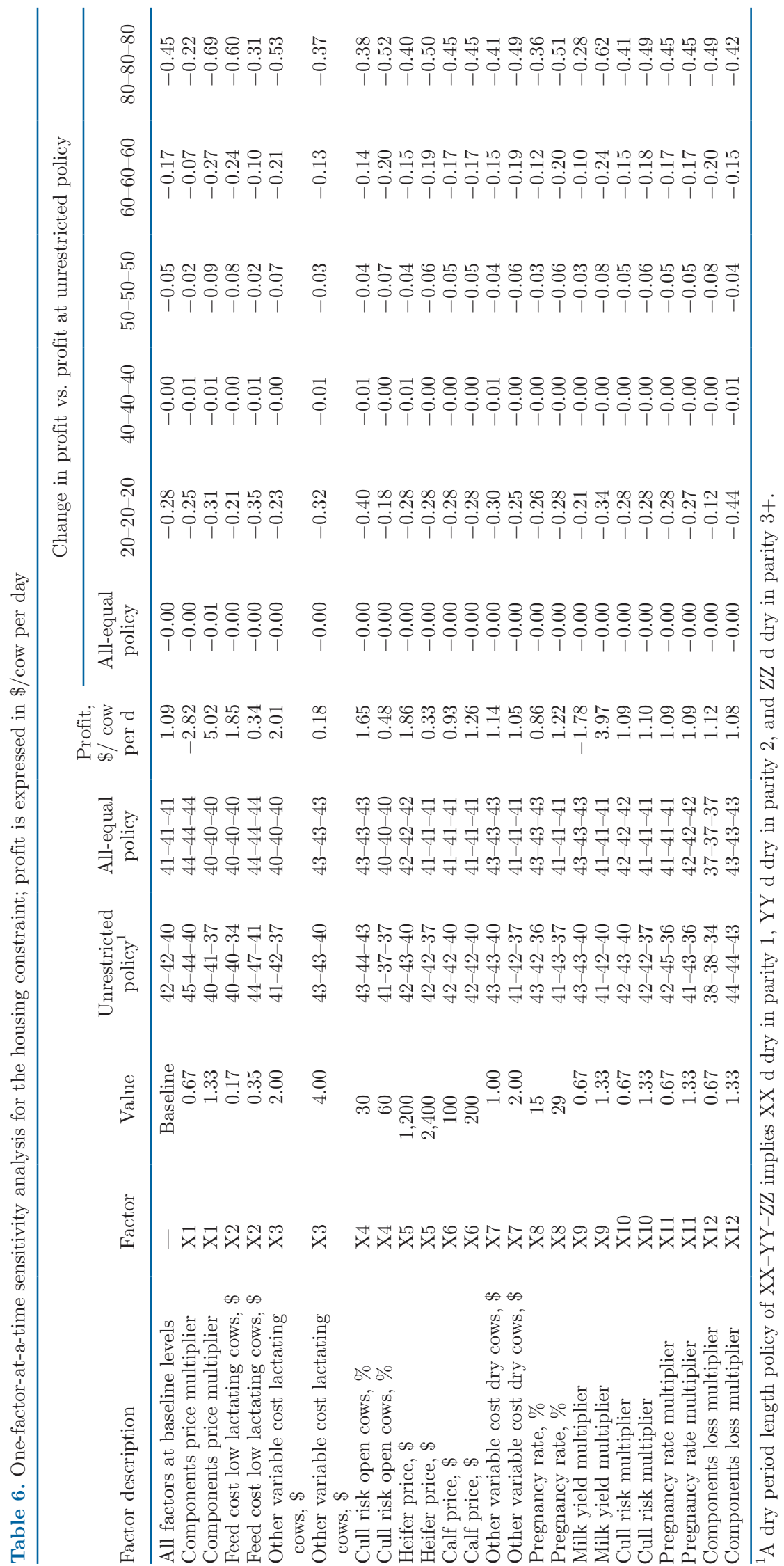




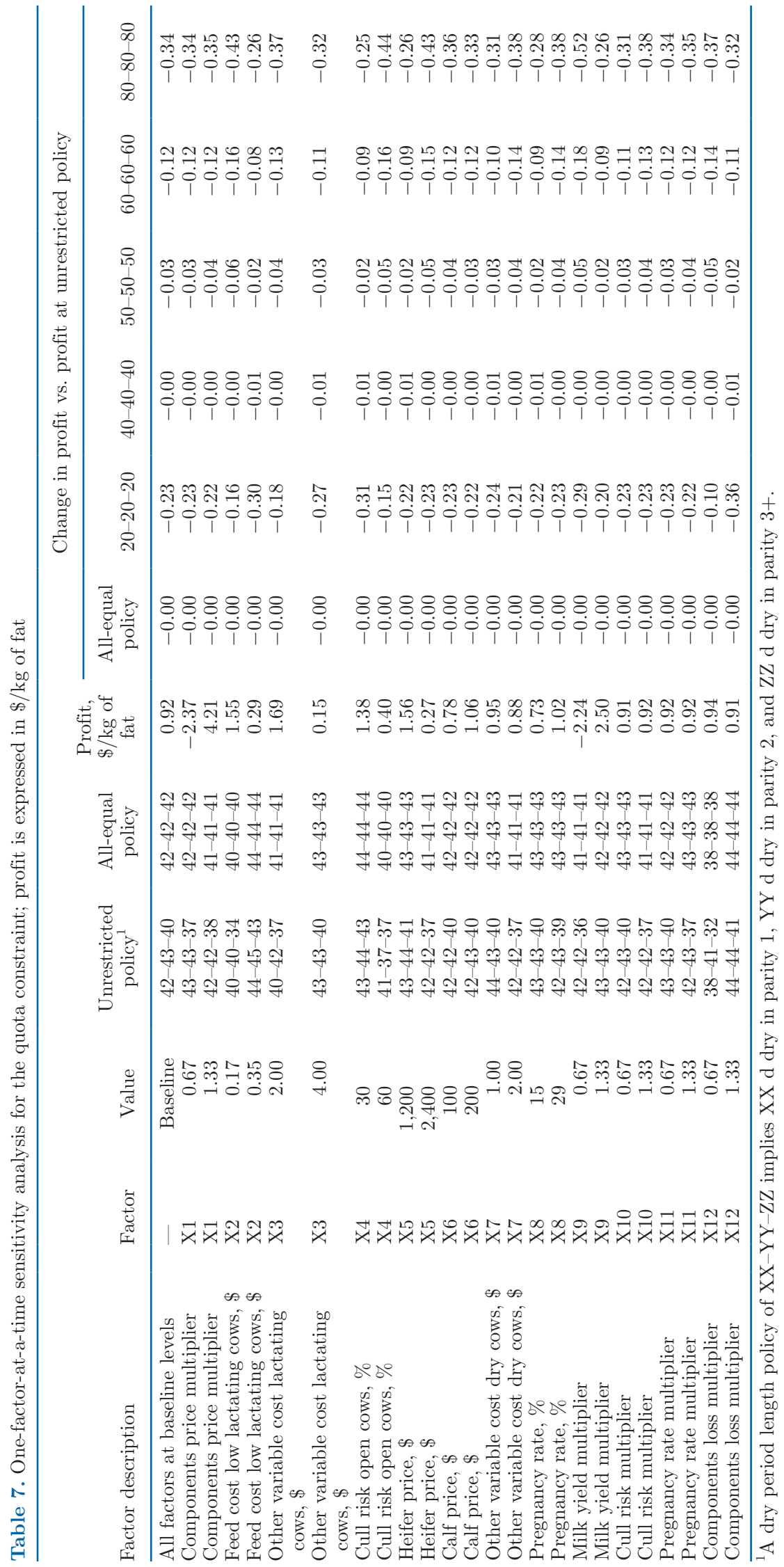


from 38-38-38 [low components price (X1) or low milk yield (X9)] to 46-46-46 [high components price (X1)]. The opportunity costs for all-equal optimal policies compared with the unrestricted optimal policy was $<\$ 0.01 /$ milking cow per day for all 24 runs. The opportunity costs of the 60-60-60 policy were $\$ 0.22$ /milking cow per day at most, and no less than $\$ 0.09 /$ milking cow per day. Several factors such as other variable cost lactating cows (X2) and cull risk multiplier (X10) had minor effects on the optimal policies.

The trends in OAT analysis under the housing constraint (Table 6) were similar to those under the parlor constraint, but the optimal DPL were generally a few days shorter. However, the optimal all-equal policy was longer under the housing constraint (44-44-44) than under the parlor constraint (38-38-38) for the low components price multiplier (X1). The unrestricted and all-equal optimal policies for the baseline levels of the 12 factors were 42-42-40 and 41-41-41. Opportunity costs of the 25 all-equal optimal and 40-40-40 policies versus the unrestricted optimal policy were $\$ 0.01$ / cow per day or less. Opportunity costs of the 60-60-60 policies varied from $\$ 0.07$ to $\$ 0.27 / \mathrm{cow}$ per day. The all-equal optimal policies varied from 37-37-37 [low components loss multiplier (X12)] to 44-44-44 [low components price multiplier (X1) and high feed cost low lactating cows (X2)].

Table 7 shows the results of the OAT analyses for the quota constraint. Using the baseline levels, the unrestricted and all-equal optimal policies were 42-43-40 and $42-42-42$, respectively. The unrestricted optimal and all-equal optimal DPL were generally between the longer DPL for the parlor constraint (Table 5) and the shorter DPL for the housing constraint (Table 6). The trends were again similar to those in Tables 5 and 6 . The opportunity costs of all-equal optimal and 40-4040 policies were $\leq \$ 0.01 / \mathrm{kg}$ fat. The all-equal policies varied between 38-38-38 [low components multiplier (X12)] and 44-44-44 [high feed cost low lactating cows (X2), low cull risk open cows (X4), and high components loss multiplier (X12)].

\section{Multiple Factors at a Time Analysis}

Definitive Screening Design. Table 8 shows the results of the 25 runs of the DSD for the 12 factors. The optimal policies in run 25 were necessarily the same as the baseline results in Tables 5, 6, and 7. The combinations of factor settings lead to large negative or large positive profits for some runs such as run pairs 5 and 6,7 and 8,15 and 16 , and 21 and 22. Runs with large negative or large positive profits were associated with optimal policies that had the greatest deviations from the optimal policies under the baseline factor settings (run 25). The unrestricted and all-equal optimal policies were also more variable under the parlor constraint than under the housing and quota constraints. The differences were large in some runs: in run 5 the unrestricted optimal policies were 84-84-84, 45-45-45 and 47-47-47 under the parlor, housing, and quota constraints, respectively. In the fold-over run of this pair (run 6: low and high factors settings are swapped), the optimal policies were 20-20-20, 36-36-36 and 29-29-29, respectively. For run 7, the all-equal optimal policies were 47-47-47 (parlor) and 41-41-41 (housing and quota). The fold-over run 8 resulted in all-equal optimal policies of 31-31-31 (parlor), 90-90-90 (housing), and 45-45-45 (quota). Thus, under the parlor constraint the optimal DPL became shorter but under the housing and quota constraints the optimal DPL became longer. Run 7 was very profitable and run 8 was very unprofitable.

The opportunity costs of using the unrestricted optimal policies from the baseline factor settings (run 25) were as large as $\$ 0.34 /$ milking cow per day (run 5), $\$ 0.17 /$ cow per day (run 8 ), and $\$ 0.05 / \mathrm{kg}$ of fat (runs 6 and 19). Under the quota constraint, the opportunity costs were $\leq \$ 0.02 / \mathrm{kg}$ of fat in 22 of 24 runs and $\leq \$ 0.02 /$ cow per day in 18 of 24 runs under the housing constraint. Figure 1 shows the results for the 25 runs of the DSD design where the all-equal optimal policy is plotted against the opportunity cost. The DSD analysis revealed large effects of some factor settings on optimal policies and opportunity costs.

Latin Hypercube Sampling. Figure 1 also shows the results for the 100 runs of the LHS design under the 3 farm constraints. The trends in the graphs are similar to the trends for the DSD runs. A large majority of the LHS runs led to all-equal policies that are similar to the optimal policy for the baseline factor settings, indicating that the optimal policies did not vary much when the factor levels were quasirandomly changed. In these cases, the opportunity costs were generally low. Under the parlor constraint, 3 of 100 runs led to allequal policies $\geq 50-50-50$ with one run leading to an all-equal policy of 59-59-59 and an opportunity cost of $\$ 0.16 /$ milking cow per day. Under the housing constraint, the all-equal optimal policies varied between 34-34-34 and 71-71-71 with opportunity cost $\leq \$ 0.12 /$ cow per day. Under the quota constraint, the all-equal optimal policies varied between $35-35-35$ and 48-48-48 with opportunity cost $\leq \$ 0.04 /$ cow per day.

Factor Screening. Factor screening results are shown in Table 9. The first 9 steps after inclusion of the intercept are shown. As expected, adding effects in the first few steps increased the model $\mathrm{R}^{2}$ the most, and the absolute values of the standardized regression coef- 
Pattamanont and De Vries: DRY PERIOD LENGTH AND FARM CONSTRAINTS

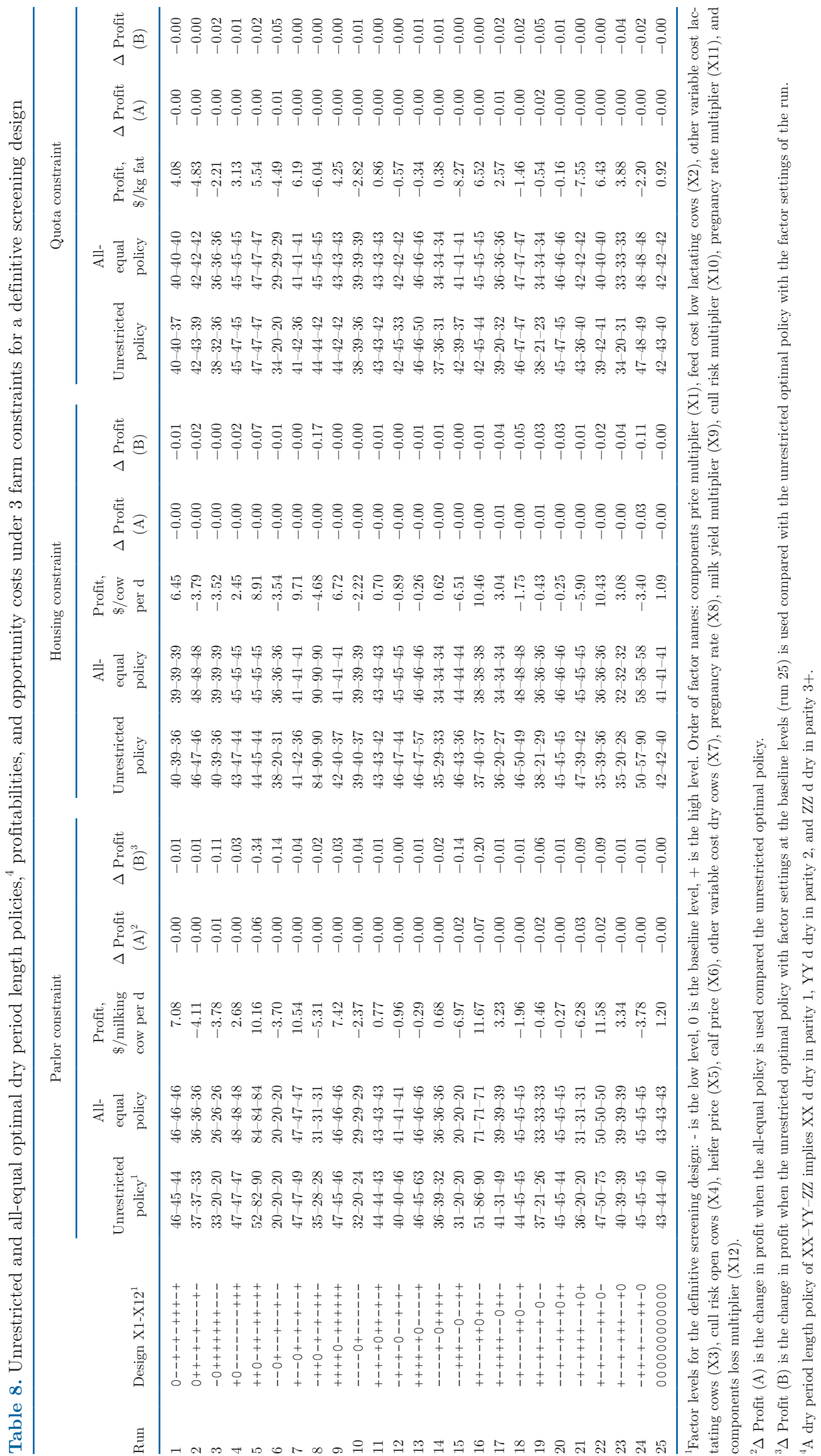




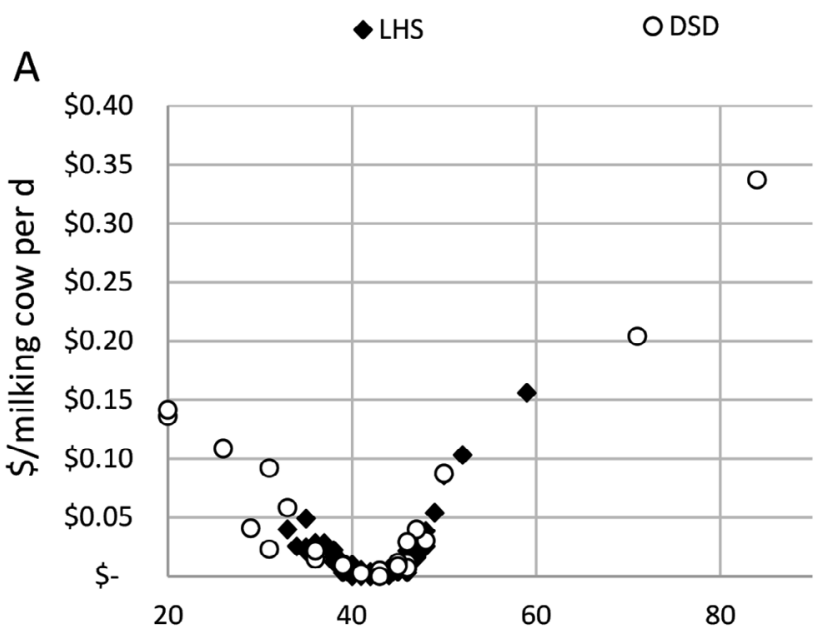

All-equal optimal dry period length, $d$

B

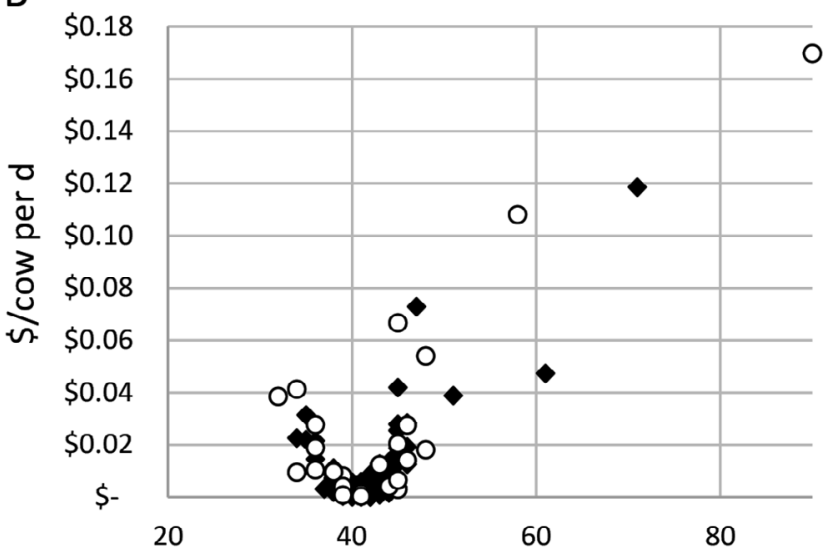

All-equal optimal dry period length, $d$

C

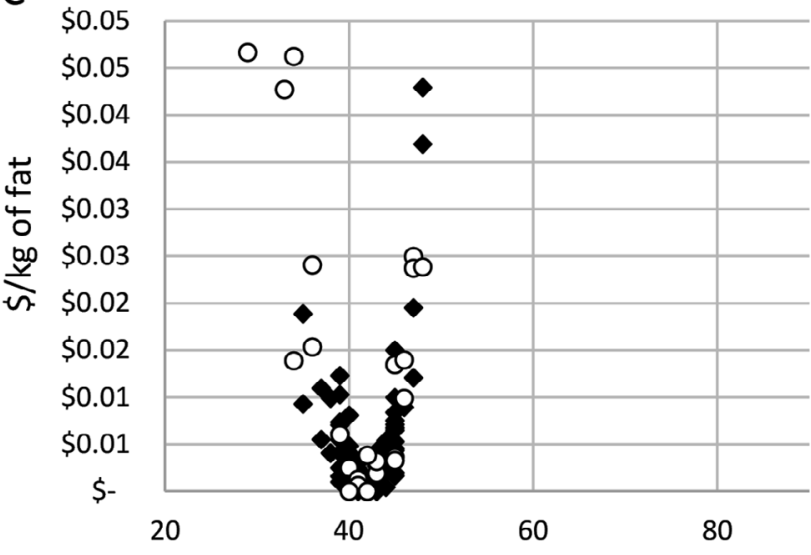

All-equal optimal dry period length, $d$

Figure 1. Opportunity cost and all-equal optimal dry period length for 100 runs with the Latin hypercube sampling design and 25 runs of the definitive screening design under (A) parlor, (B) housing, and $(\mathrm{C})$ quota constraints. Opportunity cost is calculated as the profit not realized if the unrestricted optimal dry period length policy for the baseline factor settings is used instead of the unrestricted optimal policy associated with the factor settings of the run. ficients for those effects were generally the largest when the response variable was DPL. The increase in model $\mathrm{R}^{2}$ and size of the absolute values of the standardized regression coefficients were smaller when opportunity cost was the response variable. The order in which the effects were entered, and the factors included in the effects, varied by farm constraint and response variable. However, several similarities are observed. The effects selected under the parlor constraint varied more from those selected under the housing and quota constraints, which were more similar.

Under the parlor constraint, the factors components price multiplier (X1), milk yield multiplier (X9), and cull risk of open cows (X4) were most important for the DPL response variable. No interaction effect was entered. For the response variable opportunity cost, the 3 most important factors were components loss multiplier (X12), milk yield multiplier (X9), and cull risk of open cows (X4). Their 3 interaction effects were also entered under the parlor constraint.

Under the housing and quota constraints, the 2 most important factors when the response variable was DPL were components loss multiplier (X12) and feed cost low lactating cows (X2). When the response variable was opportunity cost, important factors were cull risk of open cows (X4) and other variable cost dry cows (X7). Several interactions were included.

The first 7 steps for the response variable DPL for all 3 farm constraints included only main effects, an indication that OAT analysis to determine important factors might be adequate for this response variable. The entered effects for the response variable opportunity cost included more second-order effects. The first selected interactions for opportunity cost were $\mathrm{X} 9 \times$ $\mathrm{X} 12, \mathrm{X} 2 \times \mathrm{X} 4$, and $\mathrm{X} 4 \times \mathrm{X} 7$. Therefore, we further analyzed the effect of these 3 interactions on optimal policies and opportunity costs.

Interactions. Table 10 shows interactions between the milk yield multiplier (X9) and components loss multiplier (X12) under the 3 farm constraints. As before, the optimal policies varied most under the parlor constraint: the all-equal policies varied from 32-32-32 to 47-47-47. Opportunity costs of the all-equal policies compared with the unrestricted optimal policy were $\leq \$ 0.01 /$ milking cow per day in all but one of the 27 runs. Interactions between X9 and X12 were small for profit, which was primarily the result of the factor setting for milk yield multiplier (X9). Given the X9 level, greater X12 levels increased the DPL of the all-equal optimal policies. Thus, the X $9 \times \mathrm{X} 12$ interactions were not large in Table 10. The largest opportunity costs for long DPL existed when the milk yield multiplier (X9) was low under the parlor and quota constraints. However, under the housing constraint the opportunity 
Table 9. Forward effect selection summary of the first 9 steps using the second-order polynomial model of 12 input factors ${ }^{1}$

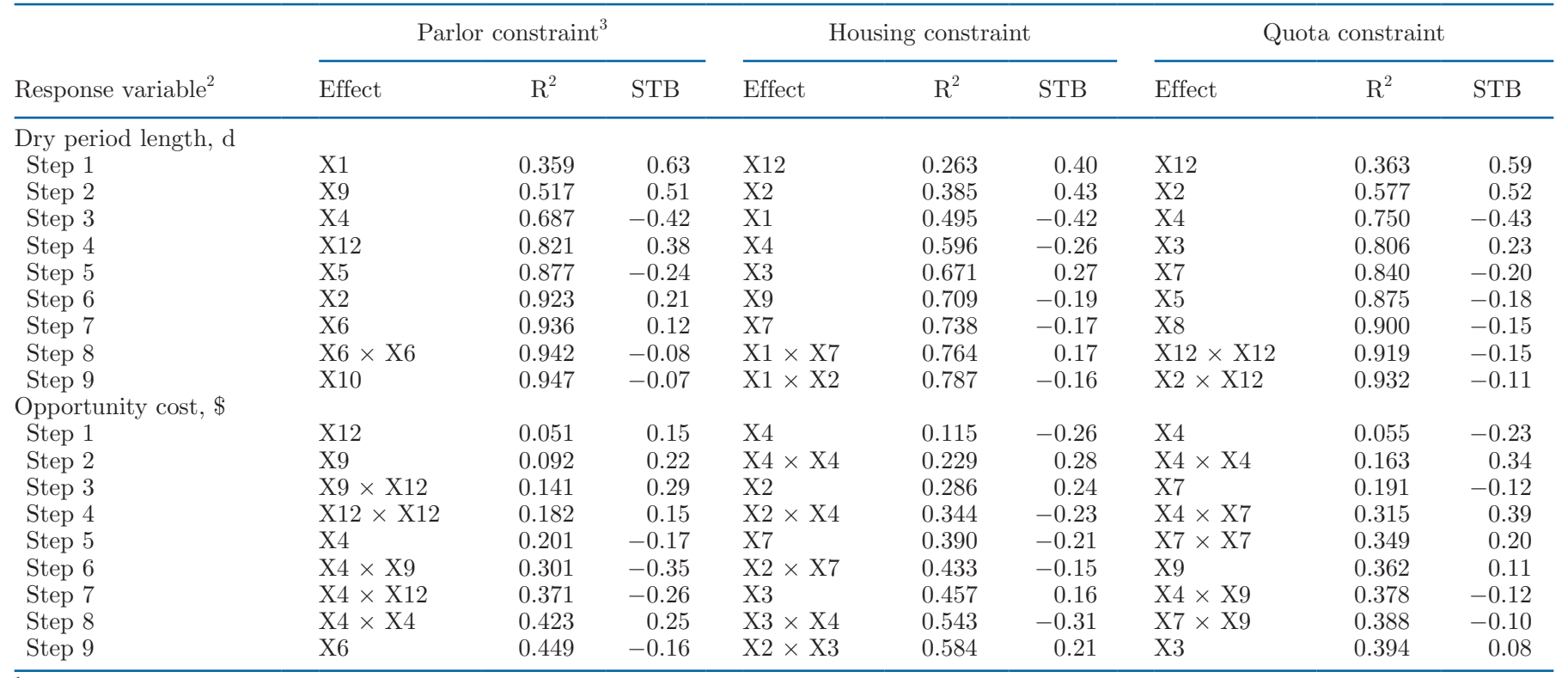

${ }^{1}$ Factor settings were varied in 100 runs using Latin hypercube sampling. The response variables are dry period length of the all-equal optimal policy and opportunity cost of using the unrestricted optimal policy given the baseline results instead of the optimal policy that results from the factor settings of the run. Factors: $\mathrm{X} 1=$ components price multiplier; $\mathrm{X} 2=$ feed cost low lactating cows; X $3=$ other variable cost lactating cows; $\mathrm{X} 4=$ cull risk open cows; $\mathrm{X} 5=$ heifer price; $\mathrm{X} 6=$ calf price; $\mathrm{X} 7=$ other variable cost dry cows; X8 = pregnancy rate; X9 $=$ milk yield multiplier; X10 = cull risk multiplier; X11 = pregnancy rate multiplier; X12 = components loss multiplier. Hierarchy was not enforced. Therefore, 2-way interactions could enter the model before their main effects were entered.

${ }^{2}$ In step 0 the intercept was added to the models.

${ }^{3} \mathrm{R}^{2}$ of the model; STB $=$ standardized regression coefficient.

cost were larges when the milk yield multiplier (X9) was highest.

Interactions between the feed cost of low lactating cows (X2) and cull risk open cows (X4) are shown in Table 11. The all-equal policies varied from 37-37-37 (housing and quota constraints) to $47-47-47$ (parlor constraint). Interactions were similar: high feed cost of low lactating cows (X2) and low cull risk open cows (X4) lead to the longest all-equal optimal DPL under all 3 farm constraints. The maximum opportunity costs for the 60-60-60 policy were $\$ 0.25 /$ milking cow per day, $\$ 0.28 /$ cow per day, and $\$ 0.21 / \mathrm{kg}$ of fat.

The third interaction we investigated was between cull risk open cows (X4) other variable cost dry cows (X7) (Table 12). The all-equal optimal policies varied between 38-38-38 (housing and quota constraints) and 46-46-46 (parlor constraint). The maximum opportunity costs compared with the 60-60-60 policy were $\$ 0.23 /$ milking cow per day, $\$ 0.22 /$ cow per day, and $\$ 0.18 / \mathrm{kg}$ of fat. For all 3 farm constraints, profit was greatest when both the cull risk open cows and other variable cost dry cows were low. Thus, the level of the second factor modified the all-equal optimal policy and opportunity cost. The analyses of these 3 interactions showed that opportunity costs maybe be meaningfully different when the second factor settings were varied given the levels of the first factors.

\section{DISCUSSION}

In this study, we evaluated the effect of parlor, housing, and quota constraints on the optimal DPL policy, and the opportunity cost of user-defined, nonoptimal policies. We also conducted a global sensitivity analysis where we used a formal design of computer experiment process to find the most active effects among 12 factors. Finally, we investigated the most active 2 -way interactions. The results showed that the optimal DPL was often longest but also most variable under the parlor constraint. The design of computer experiment process revealed important interactions that would remain hidden with an OAT analysis.

\section{Evaluation of Optimal DPL and Opportunity Costs}

Using the baseline factor settings, the optimal policies were 43-44-40, 42-42-40, and 42-43-40 for the parlor, housing, and quota constraints, respectively. We observed that the unrestricted optimal policies were sensitive to the starting settings of the optimizer; the 
Pattamanont and De Vries: DRY PERIOD LENGTH AND FARM CONSTRAINTS

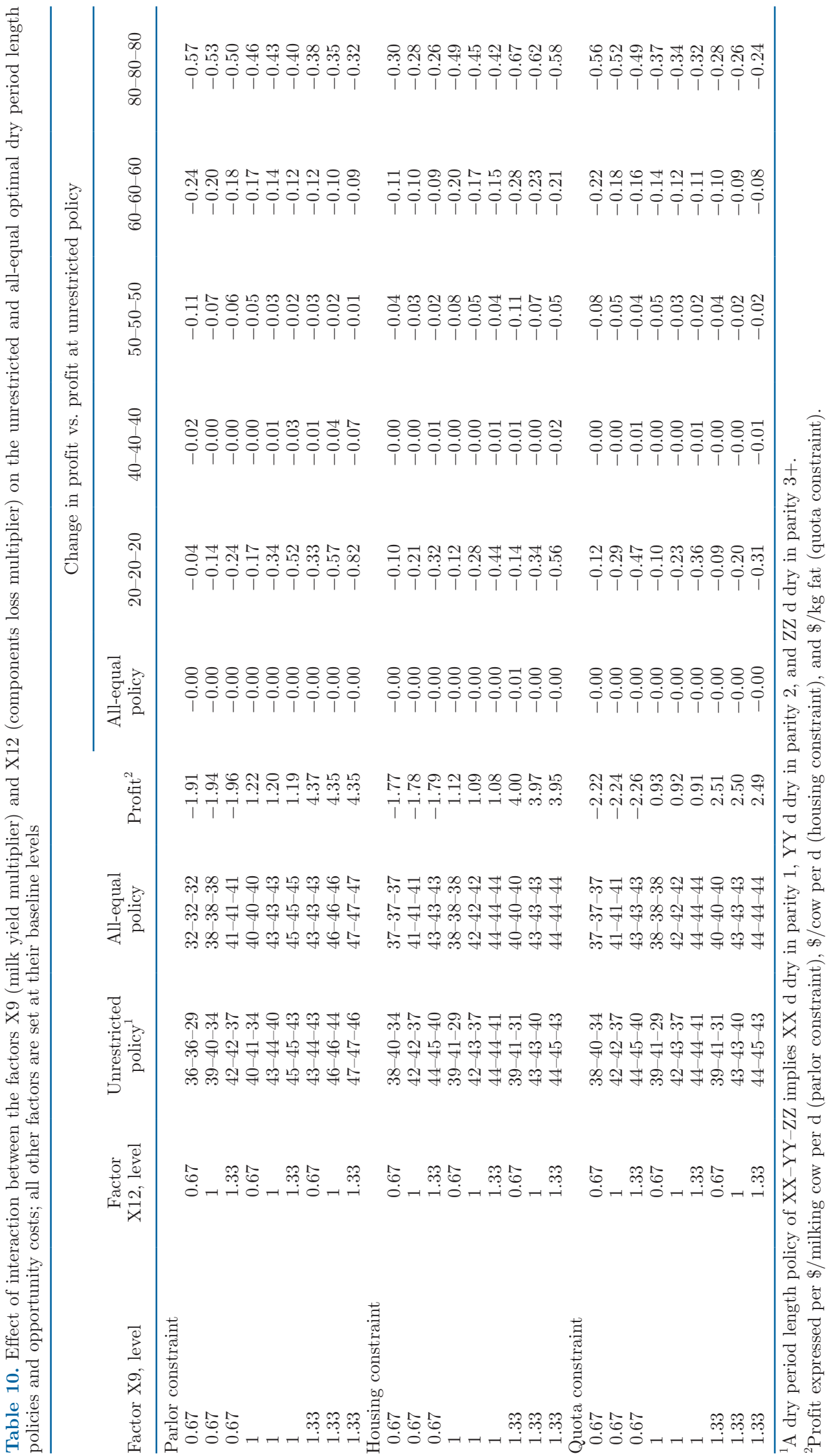


Pattamanont and De Vries: DRY PERIOD LENGTH AND FARM CONSTRAINTS

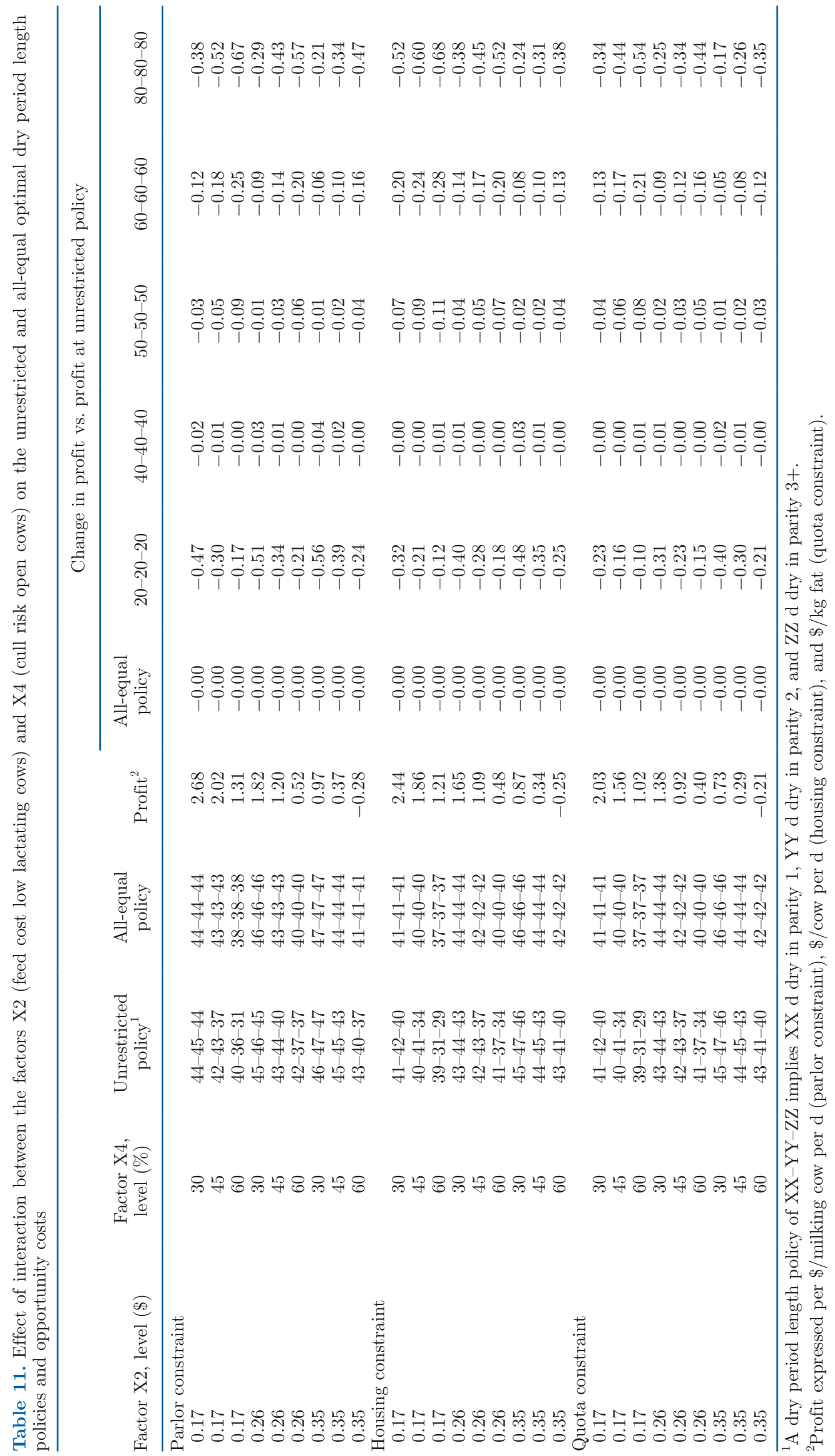


Pattamanont and De Vries: DRY PERIOD LENGTH AND FARM CONSTRAINTS

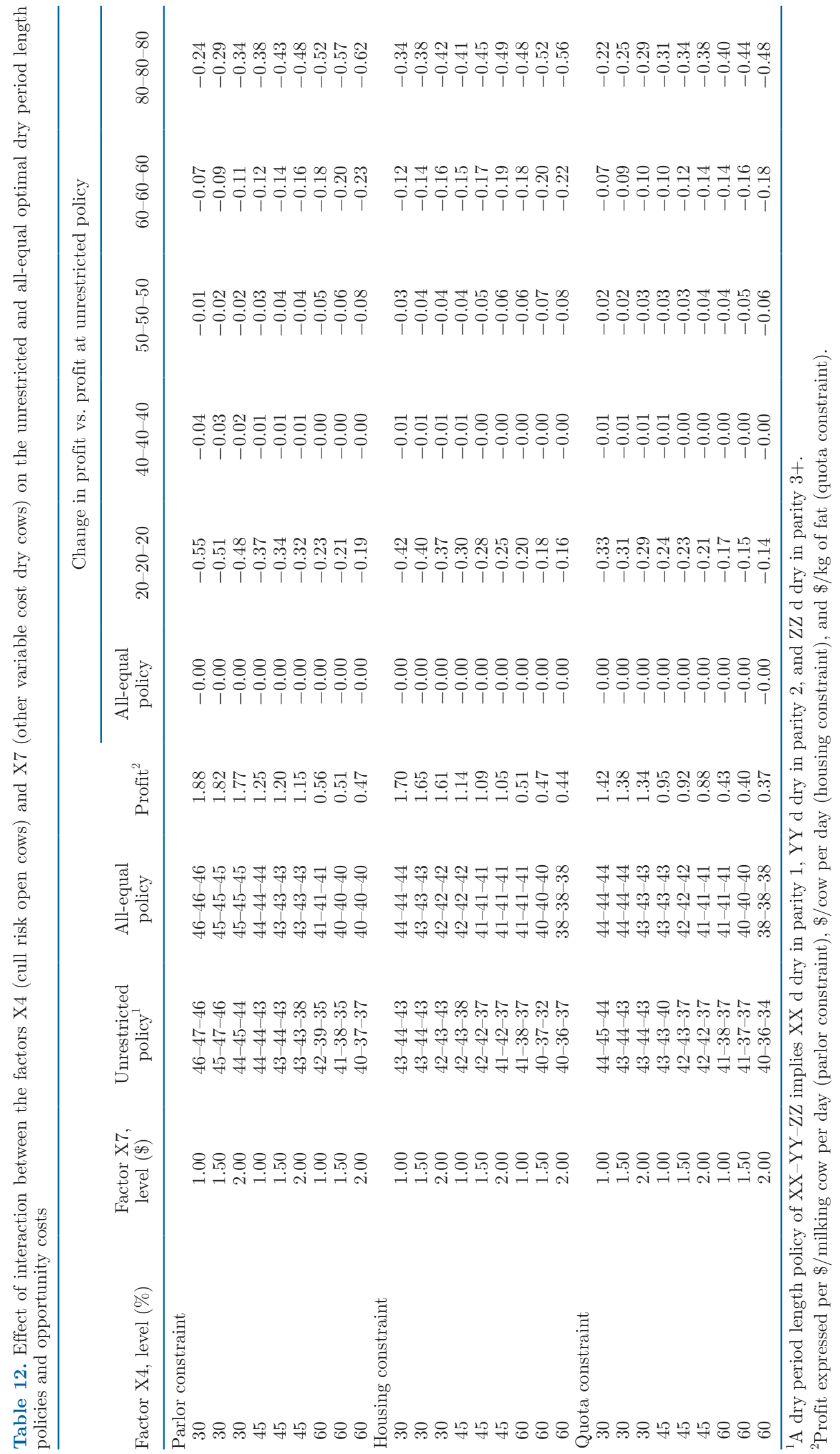


DPL of the third and greater parity (the third number in the 3-number policy sequence) could vary significantly. However, the starting settings had little effect on the herd profit. The all-equal optimal policies were not sensitive to the starting settings.

The all-equal optimal DPL of 43 (parlor), 41 (housing), and 42 (quota) d given our baseline factor settings are shorter than the average DPL observed in practice $(\geq 54 \mathrm{~d})$ as reported by Pattamanont et al. (2021b). These optimal DPL remained similar for many variations in factor settings. Yet opportunity costs of a 50-d DPL were generally small. A DPL of 42 to $56 \mathrm{~d}$ was favored more than $100 \mathrm{yr}$ ago (Arnold and Becker, 1936). Based on physiological but not economic arguments, Collier et al. (2012) concluded that first-parity cows require a 60-d dry period, but older cows might not see a reduction in performance with shorter DPL, such as $30 \mathrm{~d}$. We did not find economic evidence that first-parity cows required longer DPL. Our optimal DPL were about $7 \mathrm{~d}$ shorter than the 49 d reported by Sørensen et al. (1993). Opportunity cost versus $42 \mathrm{~d}$ appeared small in their study, however. Our shorter than observed DPL in practice agree with Santschi et al. (2011) where a DPL of 35 d was preferred over $60 \mathrm{~d}$ under both a housing and quota constraint. Heeren et al. (2014) reported that omitting the DPL was more profitable than the $60 \mathrm{~d}$ DPL under a milk quota constraint. We did not evaluate a 0-d DPL. However, DPL shorter than $30 \mathrm{~d}$ were rare in our results: 4 of the 25 DSD runs resulted in allequal DPL $<30 \mathrm{~d}$ under the parlor constraint. One of the 25 DSD runs under the quota constraint resulted in DPL $<30 \mathrm{~d}$. The profitability in all these runs was very negative.

The optimal DPL policy for a milk price based on fat and protein content is longer than when the milk price is independent of fat and protein content. Using a price of $\$ 0.37 / \mathrm{kg}$ milk, the all-equal optimal DPL were 47,45 , and $46 \mathrm{~d}$ for the parlor, housing, and quota constraints, respectively. Optimization of herd milk yield revealed optimal all-equal policies of 90,41 , and $90 \mathrm{~d}$ for the parlor, housing, and quota constraints.

As hypothesized, the optimal DPL were often longest under the parlor constraint, although the increases were on average minor. Under this constraint, cows need to be dried off sooner so that higher producing cows can be milked, and the amount of milk harvested per unit of milking time increases. Cows should have longer DPL when the cost of keeping dry cows decreases. However, there were important exceptions to this rule as illustrated in Table 8 where in 6 of the 25 runs the all-equal DPL were longest under the housing constraint. The optimal all-equal DPL of the quota constraint were never longer or shorter than the optimal all-equal DPL under the parlor and housing constraints.

Although the optimal DPL policy under various farm constraints and factor settings is of some interest, the opportunity cost of nonoptimal policies may be more relevant. One finding was that the opportunity cost of an all-equal optimal policy versus the unrestricted optimal policy was very small and negligible in practice. This finding was also reported by Sørensen et al. (1993). The opportunity cost of the 20-20-20 policy was generally greater than the opportunity cost of the 60-60-60 policy, but not in all cases.

Dairy farmers are likely not able to determine the optimal DPL policy in steps of days or weeks, considering the complexity of evaluating the net effect of a policy on farm profitability under a farm constraint. Their DPL policy may be a result of past advice of a longer DPL of, say, 60 d (Knight, 1988). However, longer DPL may also be motivated by a risk analysis, for example because the date of calving is unknown. Earlier than expected calving may lead to large reductions in the cow's performance in the subsequent parity, especially when dry cows are not managed for short DPL, such as with feeding appropriate dry cow rations (Olagaray et al., 2020). Therefore, longer DPL than found to be optimal in our study are not irrational.

Although the opportunity costs of the all-equal optimal policies compared with the unrestricted optimal policies were generally very small, individual cows within the same parity may need different DPL. For example, cows with higher SCC are given longer DPL in practice (Pattamanont et al., 2021b). In a 2014 USDA survey, $81 \%$ of dairy farms dried off some cows based on a minimum milk yield instead of a fixed schedule based on days pregnant (USDA-APHIS, 2016). In a German survey, dry-off decisions depended on the farm's and cow's needs (Bertulat et al., 2015). Future research should develop economically optimal and practical decision rules for dry-off decisions for individual cows.

The OAT (Tables 5, 6, and 7) and factor screening sensitivity analyses (Table 9) identified several important factors as determinants of the optimal policy. Collectively, increased cost of culling generally decreased the optimal DPL, whereas greater milk production and greater value of milk increased the optimal DPL. Higher feed cost of the low lactating cows and lower other variable cost of dry cows increased the optimal DPL as was expected. Milk production and value were more important factors under the parlor constraint. Factors that varied the optimal DPL most generally also had the highest opportunity costs. However, important interactions were found that make it difficult to generalize the importance of individual factors. 


\section{Modeling Framework}

The results depend on the used modeling framework, the modeled effect of DPL on cow performance, and choice of prices. Using piecewise and quadratic functions, we modeled the biological effect of DPL on milk yield, pregnancy rate, and culling rate only in the subsequent parity. Some evidence exists that the reduction in milk yield was less when short DPL were applied in several consecutive parities (Rémond and Bonnefoy, 1997; Kok et al., 2017).

The results given the baseline factor settings (Tables 2,3 , and 4) are realistic compared with averages for herd metrics for thousands of dairy herds as found in DairyMetrics (DRMS, 2020). However, a database that represents the entire dairy industry is not available in the United States, and herd metrics from the literature vary in time, place, and selection of herds. We did not aim to choose our baseline factor settings such that our model results exactly matched average results from publicly available data sources or the literature. Therefore, only informal external validation was possible.

Our model did not include the effect of DPL on mammary health (Collier et al., 2012). However, these effects are already mostly included in the piecewise and polynomial functions for milk yield, pregnancy rate and culling rate. There is some evidence that the risk of mastitis in the subsequent parity increases when milk yield at dry-off increases (Rajala-Schultz et al., 2005). This effect suggests a shorter DPL is advantageous, both because the cow is later in lactation and the progressing gestation further reduces milk yield. Treatment cost for mastitis and other diseases were not included in our model, however. Shorter DPL may lead to fewer metabolic diseases (Kok et al., 2019) which will further advantage shorter DPL. Other possible effects of DPL such as on colostrum quality are also not recognized in our results.

Although the DPL affected milk yield, pregnancy rate, and culling rate only in the subsequent parity, collectively they affected the optimal DPL for all parities. Therefore, the effect of the DPL propagated to parities beyond the subsequent parity. This extended propagation implies that an economic evaluation of the DPL policy should not be limited to the sum of the profitability of 2 consecutive parities, a finding in agreement with Sørensen et al. (1993). Optimal DPL of multiple parities are not independent.

Our deterministic model has 1 DIM at conception (days open) and 1 lactation curve for milk, fat, and protein per parity. We did not evaluate differences in cow performance within parity. A future extension should be to model different performances of cows within the same parity, for example variation in days open and variations in milk production. Such an extension could mimic a herd of individual cows. Consequently, every individual cow would have her own optimal DPL and opportunity costs. Individual DPL optimization would further increase farm profitability. However, it is not clear how such extensions would affect the average optimal DPL that are presented in the current study. Variations in days open had little effect on the optimal DPL policy in the current model, in contrast to the finding of O'Connor and Oltenacu (1988). Variations in herd milk yield had greater effects. Further, the DPL of individual cows affects their contribution to the farm milking capacity and farm fat quota. Therefore, the optimal DPL of individual cows is dependent on the DPL solution for other cows under the parlor and quota constraints.

We chose baseline factor settings based on the available information to us and our own experiences. Detailed data on variable cost associated with the DPL across many farms are not publicly available and therefore some uncertainty remained when choosing baseline factor settings. Sensitivity analysis was conducted in part to evaluate the effect of uncertainty about factor settings on the optimal DPL. In addition, the effect of variations in the DPL on farm profit, and therefore the optimal DPL, depends primarily on the daily cost of the late lactation group and the daily cost in the dry period between 90 and $20 \mathrm{~d}$ dry. This is typically the far-off dry group. Increased variable cost per far-off day decreases the optimal DPL. Variations in the cost of other factors associated with the dry period, such as the cost of drying-off management, vaccines, close-up ration cost, additional bedding and labor, calving cost, and calf revenue do not depend on the DPL and can be considered fixed for a dry period of any length. Therefore, variations in these factors had minimal effects on the optimal DPL (data not shown).

Our deterministic framework did not allow for inclusion of uncertainty about the DPL. In practice, the actual length of the DPL is unknown at dry-off because the date of calving is not known with certainty. Part of the uncertainty of the date of calving can be explained by known causes, such as the sex of the calf, twins, or season, but variation remains. Norman et al. (2009) reports a standard deviation of $5.3 \mathrm{~d}$ for gestations length for Holsteins. Including this stochasticity around the DPL in a piecewise model may increase the expected loss in milk, fat, and protein yield in the subsequent lactation because the losses are not symmetric around the expected DPL. Depending on the position of the expected DPL in the piecewise model, adding Gaussian stochasticity either increases the expected reductions in milk, fat, or protein or has no effect. The largest effects are around $40 \mathrm{~d}$ dry. A stochastic model with 
standard deviation of $5.3 \mathrm{~d}$ increases the expected reductions by at most $150 \mathrm{~kg}$ of fat, $4 \mathrm{~kg}$ of fat, and $4 \mathrm{~kg}$ of protein per 305-d ME lactation. These reductions are similar to reductions modeled by the high end of our components loss multiplier (Tables 5, 6, and 7). The sensitivity analyses show that assuming these greater reductions in fat and protein yield in the subsequent lactation would increase the optimal DPL by 2 to $4 \mathrm{~d}$. Considering stochasticity for other input factors related to the dry period likely has no effect on the optimal DPL. Adding stochasticity into an economic analysis might increase the optimal DPL, but the effects would likely be minor. The addition of uncertainty in DPL on economically optimal DPL warrants more research, however. Optimization of individual cow decisions, such as DPL, under farm constraints was not feasible in the past (Kristensen, 1992) and was outside the scope of this study.

\section{Farm Constraints}

We modeled 3 farm constraints that may be relevant in nonseasonal herds. The parlor constraint often applies to large dairy farms in the United States where milking capacity is the most limiting factor. The parlor constraint also applies to automatic milking systems. However, dairy farmers have other options under parlor constraints, such as changing the milking frequency of groups of cows or changing parlor throughput. We did not attempt to exactly model existing quota systems, such as in Canada. If the quota is annual, cows may be dried off early toward the end of the annual quota period to avoid milk production over the quota. Also, the housing constraint can be mitigated by changes in the stocking density (De Vries et al., 2016). Other farm constraints could affect the optimal DPL, for example when milk pricing depends on the seasonality of herd milk production. Stocking density of dry pens (Olagaray et al., 2020), labor availability, and the availability of feed are other examples. We also did not consider the transition from one DPL policy to another DPL policy as explored by Kok et al. (2017).

\section{Design of Experiments}

In this this study we applied a formal process to determine important factors and their interactions. Many analyses of complex nonlinear simulation models do not go beyond simple OAT analyses (Czitrom, 1999; Saltelli et al., 2019), a limitation we also have observed in the dairy science literature. In addition, our model speed limited the number of runs to a few hundred within a reasonable amount of time $(<8 \mathrm{~h})$. Therefore, factor settings should be carefully chosen to learn as much as possible about active effects with a limited number of runs. Definitive screening designs offer advantages compared with more traditional experimental designs such as fractional-factorial and Plackett-Burman designs (Jones and Nachtsheim, 2011) and have been rapidly accepted by (physical) experimenters worldwide (Goos, 2016). Desirable properties of DSD include (1) they have orthogonal main effects, (2) the 2-factor interactions are uncorrelated with the main effects, (3) the quadratic effects are uncorrelated with the main effects (but may be correlated with the 2-factor interactions), (4) all quadratic effects are estimable, (5) the number of runs is only one more than twice the number of factors, and (6) the designs can estimate all possible full quadratic models involving 3 or fewer factors. However, preliminary analyses showed that the number of active effects as determined by forward selection was sometimes greater than half the number of runs $(>13$, data not shown), which reduces the ability of the DSD to elicit active effects (Errore et al., 2017). Therefore, we also used a space-filling design with LHS. Space-filling designs are useful for modeling systems that are deterministic or near-deterministic (Santner et al., 2003) such as our model.

We used the originally suggested full quadratic polynomial model with forward selection for DSD to determine important effects (Jones and Nachtsheim, 2011), even though we did not use the DSD runs but the LHS runs for factor screening. The DSD might be extended with fake factors and extra runs and become more useful for factor screening with our deterministic model. Compared with forward selection, the analytical approach for DSD proposed by Jones and Nachtsheim (2017) takes explicit advantage of the special structure of DSD and might rank the importance of factors differently. That analysis was beyond the scope of this study.

We chose our lowest and highest factor setting somewhat arbitrary and at equal distance from the baseline settings ( $67 \%$ and $133 \%$ ). These settings seemed plausible when considered by themselves but combined might lead to unrealistic profit metrics as Table 8 showed. It is not necessary to have equal distanced factor settings for the experimental designs DSD and LHS to be valid and will lead to similar but not necessarily identical factor screening outcomes (data not shown). For factor screening, the low and high settings for each factor must be chosen "bold, but not foolish" (NIST/SEMATECH. 2012). Carefully designed computer experiments deserve more attention in the analysis of dairy systems models. Introductions are found in Santner et al. (2003) and Saltelli et al. (2004), among others. 


\section{CONCLUSIONS}

This study showed that the economically optimal DPL were typically between 35 and $50 \mathrm{~d}$ under a large variation in input factor settings. The opportunity cost of policies where the DPL were required to be the same in all parities were small compared with optimal policies where the DPL could vary between parities. The DPL under the parlor constraint were generally a few d longer compared with the optimal DPL under the housing constraint. The optimal DPL under the fat constraint were a few days longer compared with the housing constraint. The optimal DPL under the parlor constraint were more sensitive to variations in factor settings than the housing and quota constraints. Opportunity costs compared with $50 \mathrm{~d}$ dry were often small. A formal global sensitivity analysis revealed important interactions of input factors that were not discovered with the OAT analysis. Future research may develop economically optimal and practical decision rules for dry-off decisions for individual or groups of similar cows and should include uncertainty about the DPL when the dry-off decision is made.

\section{ACKNOWLEDGMENTS}

Pornpamol Pattamanont thanks the Department of Livestock Development, Ministry of Agriculture and Cooperatives, Thailand, and The Royal Thai Government for the financial support of her graduate studies. We thank Bruno do Amaral, Progressive Dairy Solutions (Oakdale, CA), who helped us select some input factor settings. Final settings were made by the authors. We also thank 2 anonymous reviewers and the section editor for comments that improved the quality of this paper. The authors have not stated any conflicts of interest.

\section{REFERENCES}

Arnold, P. T. D., and R. B. Becker. 1936. Influence of preceding dry period and of mineral supplement on lactation. J. Dairy Sci. 19:257-266. https://doi.org/10.3168/jds.S0022-0302(36)93061-8.

Bachman, K. C., and M. L. Schairer. 2003. Invited review: Bovine studies on optimal lengths of dry periods. J. Dairy Sci. 86:30273037. https://doi.org/10.3168/jds.S0022-0302(03)73902-2.

Barnard, C. S., and J. S. Nix. 1979. Farm Planning and Control. 2nd ed. University of Cambridge.

Bertulat, S., C. Fischer-Tenhagen, and W. Heuwieser. 2015. A survey of drying-off practices on commercial dairy farms in northern Germany and a comparison to science-based recommendations. Vet. Rec. Open 2:e000068. https://doi.org/10.1136/vetreco-2014 -000068 .

Bohmanova, J., J. Jamrozik, and F. Miglior. 2009. Effect of pregnancy on production traits of Canadian Holstein cows. J. Dairy Sci. 92:2947-2959. https://doi.org/10.3168/jds.2008-1782.

Collier, R. J., E. L. Annen-Dawson, and A. Pezeshki. 2012. Effects of continuous lactation and short dry periods on mammary function and animal health. Animal 6:403-414. https://doi.org/10.1017/ S1751731111002461.

Czitrom, V. 1999. One-factor-at-a-time versus designed experiments. Am. Stat. 53:126-131.

De Vries, A. 2006. Economic value of pregnancy in dairy cattle. J. Dairy Sci. 89:3876-3885. https://doi.org/10.3168/jds.S0022 -0302(06)72430-4.

De Vries, A., H. Dechassa, and H. Hogeveen. 2016. Economic evaluation of stall stocking density of lactating dairy cows. J. Dairy Sci. 99:3848-3857. https://doi.org/10.3168/jds.2015-10556.

De Vries, A., J. D. Olson, and P. J. Pinedo. 2010. Reproductive risk factors for culling and productive life in large dairy herds in the eastern United States between 2001 and 2006. J. Dairy Sci 93:613-623. https://doi.org/10.3168/jds.2009-2573.

Dias, F. M., and F. R. Allaire. 1982. Dry period to maximize milk production over two consecutive lactations. J. Dairy Sci. 65:136-145. https://doi.org/10.3168/jds.S0022-0302(82)82162-0.

DRMS. 2020. DairyMetrics. Dairy Records Management Systems. Accessed Nov. 7, 2020. http://retro.drms.org/DairyMetricsRun.aspx.

Ehrlich, J. L. 2011. Quantifying shape of lactation curves, and benchmark curves for common dairy breeds and parities. Bov. Pract. 45:88-96.

Errore, A., B. Jones, W. Li, and C. J. Nachtsheim. 2017. Using definitive screening designs to identify active first- and second-order factor effects. J. Qual. Technol. 49:244-264. https://doi.org/10.1080/ 00224065.2017.11917993.

FrontlineSolvers. 2020. Excel Solver - Algorithms and methods used. Accessed Nov. 9, 2020. https://www.solver.com/excel-solver -algorithms-and-methods-used.

Goos, P. 2016. Discussion of "21st century screening experiments: What, why, and how." Qual. Eng. 28:111-114. https://doi.org/10 $.1080 / 08982112.2015 .1100464$.

Heeren, J. A. H., W. Steeneveld, and P. B. M. Berentsen. 2014. Economic comparison of a sixty day dry period with no dry period on Dutch dairy farms. Livest. Sci. 168:149-158. https://doi.org/10 .1016/j.livsci.2014.08.004.

Jones, B., and C. Nachtsheim. 2017. Effective design-based model selection for Definitive Screening Designs. Technometrics 59:319329. https://doi.org/10.1080/00401706.2016.1234979.

Jones, B., and C. J. Nachtsheim. 2011. A class of three-level designs for definitive screening in the presence of second-order effects. J. Qual. Technol. 43:1-15. https://doi.org/10.1080/00224065.2011 .11917841.

Karzes, J., L. Hill, and W. Knoblauch. 2020. Progress of the Dairy Farm Report. Dairy Farm Business Summary. New York State, 2019. E.B 2020-4. ProDairy. Accessed June 12, 2021. https:// dyson.cornell.edu/wp-content/uploads/sites/5/2020/07/Progress _Report_4_updated-VD.pdf.

Knight, C. H. 1998. Extended lactation. Page 30-39 in Hannah Research Institute Yearbook 1998. E. Taylor, ed. University of Glasgow.

Kok, A., J. Chen, B. Kemp, and A. T. M. van Knegsel. 2019. Review: Dry period length in dairy cows and consequences for metabolism and welfare and customised management strategies. Animal 13(S1):s42-s51. https://doi.org/10.1017/S1751731119001174.

Kok, A., C. E. van Middelaar, P. F. Mostert, A. T. M. van Knegsel, B. Kemp, I. J. M. de Boer, and H. Hogeveen. 2017. Effects of dry period length on production, cash flows and greenhouse gas emissions of the dairy herd: A dynamic stochastic simulation model. PLoS One 12:e0187101. https://doi.org/10.1371/journal .pone.0187101.

Korver, S., J. A. M. van Arendonk, and W. J. Koops. 1985. A function for live weight change between two calvings in dairy cattle. Anim. Sci. 40:233-241. https://doi.org/10.1017/S0003356100025332.

Kristensen, A. R. 1992. Optimal replacement in the dairy herd: A multi-component system. Agric. Syst. 39:1-24. https://doi.org/10 $.1016 / 0308-521 X(92) 90002-6$.

Leclerc, H., D. Duclos, A. Barbat, T. Druet, and V. Ducrocq. 2008. Environmental effects on lactation curves included in a test-day model genetic evaluation. Animal 2:344-353. https://doi.org/10 $.1017 /$ S175173110700119x. 
McKay, M. D., R. J. Beckman, and W. J. Conover. 1979. A comparison of three methods for selecting values of input variables in the analysis of output from a computer code. Technometrics 21:239-245.

NRC (National Research Council). 2001. Nutrient Requirements of Dairy Cattle. 7th rev. ed. Natl. Acad. Sci.

NIST/SEMATECH. 2012. e-Handbook of Statistical Methods. U.S. Dept. Commerce. Accessed Nov. 10, 2020. https://doi.org/10 $.18434 / \mathrm{M} 32189$.

Norman, H. D., L. M. Walton, and J. W. Dürr. 2020. Reasons that cows in Dairy Herd Improvement programs exit the milking herd (2019). Council on Dairy Cattle Breeding. Accessed Nov. 7, 2020. https://queries.uscdcb.com/publish/dhi/dhi20/cullall.html.

Norman, H. D., J. R. Wright, M. T. Kuhn, S. M. Hubbard, J. B. Cole, and P. M. VanRaden. 2009. Genetic and environmental factors that affect gestation length in dairy cattle. J. Dairy Sci. 92:2259 2269. https://doi.org/10.3168/jds.2007-0982.

O'Connor, J. J. Jr., and P. A. Oltenacu. 1988. Determination of optimum drying off time for dairy cows using decision analysis and computer simulation. J. Dairy Sci. 71:3080-3091. https://doi.org/ 10.3168/jds.S0022-0302(88)79908-7.

Olagaray, K. E., M. W. Overton, and B. J. Bradford. 2020. Do biological and management reasons for a short or long dry period induce the same effects on dairy cattle productivity? J. Dairy Sci. 103:11857-11875. https://doi.org/10.3168/jds.2020-18462.

Pattamanont, P., K. N. Galvão, M. I. Marcondes, J. S. Clay, and A. De Vries. 2021a. Associations between dry period length and culling and pregnancy in the subsequent lactation. J. Dairy Sci. 104:8885-8900. https://doi.org/10.3168/jds.2021-20119.

Pattamanont, P., M. I. Marcondes, J. S. Clay, A. Bach, and A. De Vries. 2021b. Piecewise modeling of the associations between dry period length and milk, fat, and protein yield changes in the subsequent lactation. J. Dairy Sci. 104:486-500. https://doi.org/10 $.3168 /$ jds.2020-18363.

Pinedo, P., C. Risco, and P. Melendez. 2011. A retrospective study on the association between different lengths of the dry period and subclinical mastitis, milk yield, reproductive performance, and culling in Chilean dairy cows. J. Dairy Sci. 94:106-115. https:// doi.org/10.3168/jds.2010-3141.

Rajala-Schultz, P. J., J. S. Hogan, and K. L. Smith. 2005. Short communication: Association between milk yield at dry-off and probability of intramammary infections at calving. J. Dairy Sci. 88:577-579.

Rastani, R. R., R. R. Grummer, S. J. Bertics, A. Gumen, M. C. Wiltbank, D. G. Mashek, and M. C. Schwab. 2005. Reducing dry period length to simplify feeding transition cows: Milk production, energy balance, and metabolic profiles. J. Dairy Sci. 88:1004-1014. https://doi.org/10.3168/jds.S0022-0302(05)72768-5.

Rémond, B., and J. C. Bonnefoy. 1997. Performance of a herd of Holstein cows managed without the dry period. Ann. Zootechnie 46:3-12.
Saltelli, A., K. Aleksankina, W. Becker, P. Fennell, F. Ferretti, N. Holst, S. Li, and Q. Wu. 2019. Why so many published sensitivity analyses are false: A systematic review of sensitivity analysis practices. Environ. Model. Softw. 114:29-39. https://doi.org/10.1016/ j.envsoft.2019.01.012.

Saltelli, A., S. Tarantola, F. Campolongo, and M. Ratto. 2004. Sensitivity Analysis in Practice: A Guide to Assessing Scientific Models. John Wiley and Sons.

Santner, T. J., B. J. Williams, and W. I. Notz. 2003 The Design and Analysis of Computer Experiments. Springer.

Santschi, D. E., D. M. Lefebvre, R. I. Cue, C. L. Girard, and D. Pellerin. 2011. Economic effect of short (35-d) compared with conventional (60-d) dry period management in commercial Canadian Holstein herds. J. Dairy Sci. 94:4734-4743. https://doi.org/10 .3168/jds.2010-3596.

Sørensen, J. T., C. Enevoldsen, and T. Kristensen. 1993. Effects of different dry period lengths on production and economy in the dairy herd estimated by stochastic simulation. Livest. Prod. Sci. 33:77-90. https://doi.org/10.1016/0301-6226(93)90240-I.

USDA-AMS. 2020. Announcement of Class and Component Prices. Accessed Nov. 9, 2020. https://www.ams.usda.gov/mnreports/ dymclassprices.pdf.

USDA-APHIS. 2016. Dairy 2014: Milk Quality, Milking Procedures, and Mastitis on US Dairies, 2014. USDA-APHIS-VS-CEAHNAHMS. https://www.aphis.usda.gov/animal_health/nahms/ dairy/downloads/dairy14/Dairy14_dr_Mastitis.pdf.

USDA-ERS. 2020. Milk cost of production estimates. Accessed Nov. 9, 2020. https://www.ers.usda.gov/data-products/milk-cost-of -production-estimates/.

van Knegsel, A. T. M., S. G. A. van der Drift, J. Cermakova, and B. Kemp. 2013. Effects of shortening the dry period of dairy cows on milk production, energy balance, health, and fertility: A systematic review. Vet. J. 198:707-713. https://doi.org/10.1016/j.tvjl .2013.10.005.

VanRaden, P. M., J. B. Cole, and K. L. Parker Gaddis. 2018. Net merit as a measure of lifetime profit: 2018 revision. USDA-AIP Research Report NM\$7 (5-18). Accessed Nov. 9, 2020. https://aipl .arsusda.gov/reference/nmcalc-2018.htm.

VanRaden, P. M., A. H. Sanders, M. E. Tooker, R. H. Miller, and H. D. Norman. 2011. Daughter pregnancy rate evaluation of cow fertility. AIPL Research Report Dpr1 (11-02). Accessed Aug. 15, 2020. https://aipl.arsusda.gov/reference/fertility/DPR_rpt.htm..

\section{ORCIDS}

Pornpamol Pattamanont ( https://orcid.org/0000-0001-5391-3581 Albert De Vries @ https://orcid.org/0000-0003-4511-0388 


\section{APPENDIX}

Table A1. Parameters of the MilkBot (Ehrlich, 2011) model to predict daily milk, fat and protein yields; parameters were fitted on the yield data used in Pattamanont et al. (2021b)

\begin{tabular}{|c|c|c|c|c|c|}
\hline \multirow[b]{2}{*}{ Item } & \multicolumn{4}{|c|}{ MilkBot parameter ${ }^{1}$} & \multirow{2}{*}{$\begin{array}{c}305-\mathrm{d} \\
\text { yield }(\mathrm{kg})\end{array}$} \\
\hline & $\mathrm{a}=$ scale & $\mathrm{b}=\operatorname{ramp}$ & $\mathrm{c}=$ offset & $\mathrm{d}=$ decay & \\
\hline \multicolumn{6}{|l|}{ Milk } \\
\hline Lactation 1 & 41.742 & 39.469 & -3.746 & 0.001059 & 10,135 \\
\hline Lactation 2 & 58.138 & 39.475 & -5.149 & 0.002284 & 11,835 \\
\hline Lactation 3 & 64.253 & 41.010 & -2.581 & 0.002595 & 12,412 \\
\hline Lactation 4+ & 65.168 & 40.353 & -0.899 & 0.002686 & 12,404 \\
\hline \multicolumn{6}{|l|}{ Fat } \\
\hline Lactation 1 & 4.199 & 744.903 & 275.770 & 0.002016 & 375 \\
\hline Lactation 2 & 5.260 & 701.034 & 232.013 & 0.003072 & 433 \\
\hline Lactation 3 & 5.764 & 666.431 & 222.201 & 0.003443 & 454 \\
\hline Lactation $4+$ & 6.139 & 668.271 & 238.387 & 0.003665 & 453 \\
\hline \multicolumn{6}{|l|}{ Protein } \\
\hline Lactation 1 & 4.271 & 600.223 & 285.901 & 0.002644 & 310 \\
\hline Lactation 2 & 5.188 & 562.212 & 243.141 & 0.003587 & 362 \\
\hline Lactation 3 & 5.519 & 506.849 & 222.061 & 0.003939 & 375 \\
\hline Lactation $4+$ & 2.736 & 184.791 & 18.396 & 0.003164 & 372 \\
\hline
\end{tabular}

${ }^{1}$ MilkBot: $\mathrm{y}(\mathrm{t})=\mathrm{a} \times\{1-[\exp [(\mathrm{c}-\mathrm{t}) / \mathrm{b}] / 2\} \times \exp (-\mathrm{d} \times \mathrm{t})$, where $\mathrm{a}, \mathrm{b}, \mathrm{c}$, and $\mathrm{d}$ are parameters, $\mathrm{t}$ is DIM, $\mathrm{y}(\mathrm{t})$ is predicted yield, and $\exp ()$ is the exponential function. 